\title{
OPEN Environmental patterns of brown moss- and Sphagnum-associated microbial communities
}

\author{
Alexander Tøsdal Tveit ${ }^{1,6}$, Andrea Kiss ${ }^{2,6}$, Matthias Winkel ${ }^{2}$, Fabian Horn², Tomáš Hájek ${ }^{3}$, \\ Mette Marianne Svenning ${ }^{1}$, Dirk Wagner ${ }^{2,4}$ \& Susanne Liebner ${ }^{2,5}$
}

Northern peatlands typically develop through succession from fens dominated by the moss family Amblystegiaceae to bogs dominated by the moss genus Sphagnum. How the different plants and abiotic environmental conditions provided in Amblystegiaceae and Sphagnum peat shape the respective moss associated microbial communities is unknown. Through a large-scale molecular and biogeochemical study spanning Arctic, sub-Arctic and temperate regions we assessed how the endoand epiphytic microbial communities of natural northern peatland mosses relate to peatland type (Sphagnum and Amblystegiaceae), location, moss taxa and abiotic environmental variables. Microbial diversity and community structure were distinctly different between Amblystegiaceae and Sphagnum peatlands, and within each of these two peatland types moss taxon explained the largest part of microbial community variation. Sphagnum and Amblystegiaceae shared few ( $<1 \%$ of all operational taxonomic units (OTUs)) but strikingly abundant (up to $65 \%$ of relative abundance) OTUs. This core community overlapped by one third with the Sphagnum-specific core-community. Thus, the most abundant microorganisms in Sphagnum that are also found in all the Sphagnum plants studied, are the same OTUs as those few shared with Amblystegiaceae. Finally, we could confirm that these highly abundant OTUs were endophytes in Sphagnum, but epiphytes on Amblystegiaceae. We conclude that moss taxa and abiotic environmental variables associate with particular microbial communities. While moss taxon was the most influential parameter, hydrology, $\mathrm{pH}$ and temperature also had significant effects on the microbial communities. A small though highly abundant core community is shared between Sphagnum and Amblystegiaceae.

The majority of global wetlands are peatlands $(70 \%)^{1}$, of which $80 \%$ are natural and pristine ${ }^{2}$. Due to the high water content, low temperatures ${ }^{3}$, anoxia and the production of recalcitrant organic matter and microbial inhibitors (e.g., polyphenols) ${ }^{4}$, dead organic matter in northern peatlands decomposes slowly. Almost $20 \%$ of the global soil organic carbon and $10 \%$ of the global freshwater reservoirs are stored in peatlands ${ }^{5}$. Thus, these ecosystems fulfil crucial functions like maintaining regional water balance and sequestering carbon ${ }^{6,7}$. The vegetation of natural peatlands is dominated by bryophytes of the Amblystegiaceae family (brown mosses) and of the genus Sphagnum. Both moss types play an important role in succession and peat formation. Amblystegiaceae initialize peat formation by colonizing open water bodies ('terrestrialisation'), which leads to the formation of minerotrophic fens. Over time, Sphagnum species establish and contribute to peat accumulation ('paludification'), transforming those fens into ombrotrophic bogs ${ }^{8-12}$. The transition from a fen to an ombrotrophic bog profoundly alters the ecosystem carbon budget due to doubled net primary productivity and a fourfold decrease in the decomposition rate, causing a several fold increase in the peat accumulation rate ${ }^{13}$. Such shifts especially in vegetation have been observed to coincide with drops in $\mathrm{pH}$ from 7 to around $4^{14-16}$.

Microorganisms play a crucial role in the $\mathrm{C}$ and $\mathrm{N}$ cycles of peatlands ${ }^{17-19}$. Moss-associated microbial communities are suggested to maintain host plant health and pathogen defence ${ }^{20-24}$. In addition, moss shoots, specifically their cell walls, provide a matrix where the microorganisms can attach; additionally, cell anatomy and cell wall chemistry are expected to influence microbial community structure. Sphagnum leaves differ from Amblystegiaceae and other mosses mainly by their unique anatomy, as most of the leaf volume is formed by

${ }^{1}$ UiT The Arctic University of Norway, Department of Arctic and Marine Biology, Tromsø, Norway. ${ }^{2}$ GFZ German Research Center for Geosciences, Section Geomicrobiology, Potsdam, Germany. ${ }^{3}$ University of South Bohemia, Faculty of Science, České Budějovice, Czech Republic. ${ }^{4}$ University of Potsdam, Institute of Geosciences, Potsdam, Germany. ${ }^{5}$ University of Potsdam, Institute of Biochemistry and Biology, Potsdam, Germany. ${ }^{6}$ These authors contributed equally: Alexander Tøsdal Tveit and Andrea Kiss. ${ }^{\bowtie}$ email: susanne.liebner@gfz-potsdam.de 
empty hyaline cells possessing pores. Such cells provide the moss with efficient water conduction and retention, and provide the microorganisms with expanded surface area (inner cell walls), stable hydration and finally more acidic conditions, as the water retention is linked with the retention of acidity ${ }^{25}$.

In the arcto-alpine climate zone, plant species and geographical region were the major determinants of hostspecific endophytic bacteria ${ }^{26}$. In contrast, the effect of geographical location on Sphagnum-associated microorganisms was reported to be marginal, but vegetation, $\mathrm{pH}$ and nutrient richness may potentially determine their distribution ${ }^{27,28}$. Investigations of moss-associated microorganisms of two closely related Sphagnum species revealed highly similar diazotrophic and methanotrophic communities, whereas indicator Sphagnum mosses in Alpine bogs harboured highly specific diazotrophic bacteria ${ }^{27,29}$. Still, $50 \%$ of the Alpine bog microbiome was shared between Sphagnum, other bryophytes, vascular plants and lichens and only up to $12 \%$ where identified to be Sphagnum-specific ${ }^{30}$, suggesting site-specific 'core microbiomes' rather than moss-specific microbial communities. The presence and dominance of Acetobacteraceae in the inner tissue of Sphagnum sporophyte and in the moss-associated microbial community of the gametophyte indicate that Sphagnum species pass on parts of their microbiome from one generation to another ${ }^{31}$. It has been suggested that secondary metabolites produced by the host selects for particular bacterial communities in the Sphagnum plants ${ }^{32}$.

While Sphagnum has been the subject of several studies on peatland moss-associated prokaryotes, Amblystegiaceae have been largely neglected, despite their major role in peatland formation and predominance in pristine, minerotrophic fens especially in the Polar region ${ }^{33}$. Two comparative studies on nitrogen fixation associated with both Sphagnum and brown mosses revealed higher rates for brown mosses and overall large variations between individual moss species ${ }^{34,35}$. Additionally, it was shown that methane oxidizing bacteria are associated with submerged brown mosses, specifically with Scorpidium scorpioides ${ }^{36}$, and thus that methanotrophy is not restricted to microbial associations with Sphagnum.

There is an apparent knowledge gap regarding integrated studies on the core microbiota and biotic and environmental controls of both Amblystegiaceae- and Sphagnum-dominated peatlands. Furthermore, our knowledge of microbial endophytes of Amblystegiaceae and Sphagnum mosses is sparse and nothing is known about their role in peatland succession. We hypothesize that the two major peatland types, dominated by the two very different moss taxa Amblystegiaceae and Sphagnum, respectively, possess profoundly different microbial communities with few shared species. We designed a large-scale comparative study spanning Amblystegiaceae and Sphagnum-dominated peatlands of the Arctic, Subarctic and temperate region. We assessed pH, nutrient levels, moss taxon host-specificity, but also temperature and hydrology as potential controls on the structure and diversity of the peatland microbiota and compared the endophytic and epiphytic microbial communities to the members of the core community.

\section{Materials and methods}

Study sites and sampling. We studied two main ecosystems (Amblystegiaceae- and Sphagnum-dominated peatlands), represented by four sites, which are analogous to different stages in the transition from fens to incipient ombrotrophic bogs: 1) High-Arctic lakes with colonies of Amblystegiaceae on Svalbard (SV), Norway; 2) Arctic polygonal tundra with densely growing Amblystegiaceae on Samoylov Island (SA), Lena Delta, Russia; 3) Sub-arctic Sphagnum palsa peatlands in Neiden (NEI), Northern Norway, and 4) temperate Sphagnum kettle bogs in the Mueritz National Park (MUE), Northern Germany. An overview about the study sites and a simplified sampling scheme is given in Fig. 1, and a detailed overview of the 157 samples and the corresponding sampling sites, biotic (plant species) variables, environmental variables and geographical coordinates is provided in Tables S1A and S1B.

On SV $\left(78.9^{\circ} \mathrm{N}, 11.9^{\circ} \mathrm{E}\right)$, we sampled a mixture of submerged Amblystegiaceae from three subsites in the vicinity of Ny-Ålesund: Bryum pseudotriquetrum in Twin Water (TW), Drepanocladus trichophyllus and Scorpidium turgescens in Knudsenheia (KNU) and Drepanocladus revolvens and S. turgescens in Gludneset (GLU), each in duplicates (sample type 1; all sample types are depicted in Fig. 1). On SA $\left(72.4^{\circ} \mathrm{N}, 126.5^{\circ} \mathrm{E}\right.$ ), we sampled a mixture of submerged Scorpidium scorpioides and Meesia triquetra from an interpolygonal crack (PC; sample type $2 \mathrm{a}$ ) and $S$. scorpioides from a polygonal pond (three replicate of plants subsumed to PP; sample type $2 \mathrm{~b}$ ). At both locations, SV and SA, we collected sediment underneath the mosses as references. In NEI $\left(69.7^{\circ} \mathrm{N} ; 29.4^{\circ}\right.$ E), different successional palsa stages were selected: thermokarst ponds with Sphagnum riparium adjacent to degrading palsas (one plant within each of the subsites NEI1, NEI2; sample type 3a), thermokarst ponds with S. riparium as remnants of collapsed palsas (one plant within each of the subsites NEI3, NEI4; sample type 3c) and hollows with Sphagnum lindbergii, representing old successional stages of previously collapsed palsas (one plant within each of the subsites NEI5, NEI6, NEI7; sample type $3 \mathrm{~b}$ ). From MUE $\left(53.3^{\circ} \mathrm{N}, 13.2^{\circ} \mathrm{E}\right)$, three subsites were chosen: Heidbergmoor, a hummock-hollow complex (sample type 4a) with emerged Sphagnum fallax (three replicate plants within the subsite called HEI2) and submerged S. fallax (one plant within the subsite called HEI1); Klockenbruch, a kettle bog with an oligotrophic, elevated center (sample type 4c) with Sphagnum magellanicum (three replicate plants within KLO1) and a meso-oligotrophic, lower margin (sample type 4b) with S. fallax (three replicate plants within KLO2); Kiebitzmoor, a formerly drained and rewetted kettle bog (sample type 4c) with $S$. magellanicum (three replicate plants within KIE). In NEI we collected the sedges Eriophorum sp. and Carex sp. (NEI1, NEI5, NEI6, NEI7) and sediment underneath the mosses (NEI1, NEI2, NEI3, NEI4) as references, with duplicates for each site and reference type. In MUE, Eriophorum vaginatum (HEI2, KLO1 and KLO2) and Carex sp. (KIE) were collected as references with duplicates for each site and plant type. Sampling in all sites was done between June and September 2013.

Peat or moss batches were sampled using gloves and sterile knifes or spoons. Leafs, stem and upper root material of vascular plants were manually extracted from the peat body, washed with sterilized tap water to get rid of microorganisms that came from the surrounding environment and were not attached to the plants, cut and 


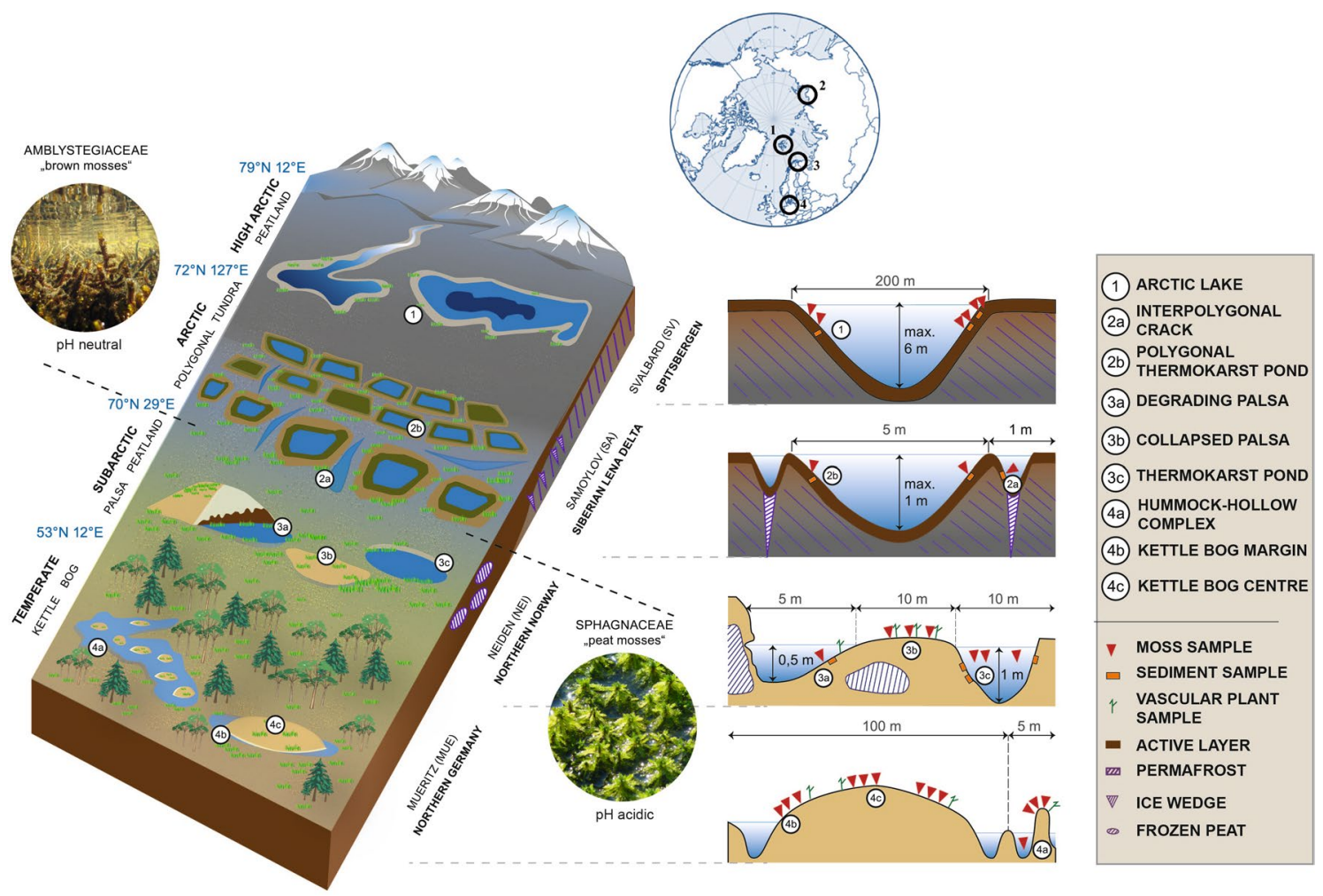

Figure 1. Schematic overview of the investigated areas and the type of samples collected. The geographical location of the sampling sites is depicted above. The different peatland types are illustrated on the left, the sampling scheme is depicted on the right. Subsampling sites are not emphasized. Illustration: Grit Schwalbe, GFZ.

used as a bulk reference sample. Complete moss individuals were sampled and also washed with sterilized tap water for removal of organisms from the surrounding environment prior to storage. All samples were stored at $-80^{\circ} \mathrm{C}$ immediately after sampling until further processing except for the samples from Samoylov Island, Lena Delta, that were continuously stored at $-20^{\circ} \mathrm{C}$.

At each site, pore water was retrieved from three depths when possible; slightly above, within and below the moss layer by extracting small samples of pore water with perforated brass tubing as described elsewhere ${ }^{37}$. At the hummock sites, pore water was extracted from the shallowest depth possible. Ten-mL plastic syringes equipped with three-way valves were connected to the brass tubes and used to carefully suck out the pore water. Pore water was transferred to gas-tight 20 -mL glass serum vials pretreated with $100 \mu \mathrm{L} 1 \mathrm{M} \mathrm{HCl}$ and pre-flushed with $\mathrm{N}_{2}$ avoiding air bubbles and stored at $4{ }^{\circ} \mathrm{C}$.

Pore water analysis $\left(\mathrm{pH}\right.$, temperature, methane, $\mathrm{DOC}$ and $\left.\mathrm{O}_{2}\right)$. Values of $\mathrm{pH}$ were measured in the field using a multi parameter probe Multi 350i from WTW (Laboratory and Field Products, Nova Analytics). Air and peat temperatures were measured with a hand-held digital thermometer 2000T (Thermocouple Thermometer, Digitron Instrumentation Ltd, England) equipped with a $50 \mathrm{~cm}$ long probe. Headspace methane concentrations were measured by gas chromatography shortly after pore water sampling as described elsewhere ${ }^{37}$. For the determination of DOC values, 20 -mL glass vials (Agilent) were flushed with ultrapure water, baked at $550{ }^{\circ} \mathrm{C}$ for $2 \mathrm{~h}$, closed with aluminium-sealed PTFE/butyl septa and acidified with 3\% HCl Suprapur (VWR). $15 \mathrm{~mL}$ of the pore water was filtered with $0.7 \mu \mathrm{m} \mathrm{GF} / \mathrm{L}$ filter (Whatman). The samples were sent to 'Potsdamer Wasser- und Umweltlabor GmbH' (PWU) for DOC analysis. Pore water $\mathrm{O}_{2}$ contents were measured in the field at different depths (above, within and below moss layer, where possible), using an optical oxygen meter (FireSting $\mathrm{O}_{2}$, PyroScience).

Cell wall analysis (CEC, HC, LLP). Cation exchange capacity (CEC). Up to $45.0 \mathrm{mg}$ of dry moss samples were sealed into labelled polyamide mesh bags. The bags were submerged in $2 \mathrm{~L}$ of $20 \mathrm{mM} \mathrm{HCl}$ to soak the moss up and to convert all carboxylic cation-exchange sites to un-dissociated form; free protons were then replaced by repeated thorough wash with distilled water. All the bags were then transferred to $2 \mathrm{~L}$ of $0.5 \mathrm{M}$ ammonium acetate and after $\mathrm{pH}$ equilibration the ammonium acetate solution was renewed and adjusted to $\mathrm{pH} 7.0 \mathrm{using}$ $\mathrm{NH}_{4} \mathrm{OH}$. The bags were repeatedly washed with large amount of distilled water to replace free $\mathrm{NH}_{4}{ }^{+}$and dried. The bags were individually immersed to $50 \mathrm{~mL}$ of $20 \mathrm{mM} \mathrm{HCl}$ and shaken for $15 \mathrm{~min}$ to elute cell-wall bound $\mathrm{NH}_{4}{ }^{+}$ions. The eluate was sampled and $\mathrm{NH}_{4}{ }^{+}$analyzed colorimetrically using Flow Injection Analysis (Foss Tecator AB, Sweden). 
Holocellulose (HC). Dry plant samples were ball-milled for $2 \mathrm{~min}$ at $30 \mathrm{~Hz}$ to fine dust (MM200, Retsch) and about $40.0 \mathrm{mg}$ of the material was washed with $5 \mathrm{~mL}$ of $70 \%$ acetone in $15-\mathrm{mL}$ Falcon tubes and oven-dried in the tubes at $48{ }^{\circ} \mathrm{C} .8 \mathrm{~mL}$ of $\mathrm{H}_{2} \mathrm{O}, 75 \mu \mathrm{L}$ of glacial acetic acid and $150 \mu \mathrm{L}$ of $25 \%$ sodium chlorite $\left(\mathrm{NaClO}_{2}\right)$ were added. The tubes were closed shaken and incubated for $1 \mathrm{~h}$ in a water bath at $75^{\circ} \mathrm{C}$, being shaken every $10 \mathrm{~min}$. The additions of acetic acid and sodium chlorite and the incubation was repeated three times. Afterwards, samples were cooled and centrifuged at $4000 \times g$ for $15 \mathrm{~min}$, supernatant was discarded. $10 \mathrm{~mL} \mathrm{H}_{2} \mathrm{O}$ was added, samples were vortexed and centrifuged at $3000 \times g$, supernatant was discarded. This wash step was repeated twice, followed by drying at $70{ }^{\circ} \mathrm{C}$. The residuum is referred to as holocellulose (structural polysaccharides) and expressed in $\%$ of dry mass.

Lignin and Lignin-like polymers (LLP). To remove phenolic extractives that can interfere with later spectrophotometric determination of acid-soluble Klason lignin, up to $60.0 \mathrm{mg}$ of milled plant material was shaken with $5 \mathrm{~mL}$ of $70 \%$ acetone in $15-\mathrm{mL}$ Falcon tubes for $1 \mathrm{~h}$. The tubes were then centrifuged, supernatant discarded and the pellets dried in the tubes at $48{ }^{\circ} \mathrm{C} .0 .4 \mathrm{~mL}$ of $72 \% \mathrm{H}_{2} \mathrm{SO}_{4}$ was added to the pellet, the tubes were vortexed and incubated for $1 \mathrm{~h}$ at $23^{\circ} \mathrm{C}$, followed by addition of $11.2 \mathrm{~mL}$ of $\mathrm{H}_{2} \mathrm{O}$, vortexing and incubation at $100^{\circ} \mathrm{C}$ for $2.5 \mathrm{~h}$. The tubes were then centrifuged at $3000 \times \mathrm{g}$ for $15 \mathrm{~min}$ and the supernatant was sampled for dissolved lignin analysis and discarded. The pellet (Klason lignin, acid-insoluble residuum) was washed three times with $10 \mathrm{~mL}$ of water, centrifuged, oven-dried at $70^{\circ} \mathrm{C}$ and expressed in $\%$ of dry mass. Acid-soluble Klason lignin was measured spectrophotometrically at $205 \mathrm{~nm}$ (standard mass attenuation coefficient of $110 \mathrm{~L} \mathrm{~g}^{-1} \mathrm{~cm}^{-1}$ was applied according to Hatfield and Fukushima 2005) and expressed in \% of dry mass. Acid-soluble Klason lignin and Klason-lignin were summed to Total Klason lignin (representing lignin-like phenolics in mosses as they lack true lignin).

Total carbon (TC), total nitrogen (TN), and C:N ratio $(\mathrm{C} / \mathrm{N})$. Plant samples were dried and milled (Pulverisette, Fritsch). About $5.0 \mathrm{mg}$ of sample was weighed in tin boats (Elementar). TC and TN contents were determined as double measurements with a carbon, nitrogen and sulfur (CNS) analyser (Elementar Vario EL III). For determining $\mathrm{C} / \mathrm{N}$, quotients of $\mathrm{TC}$ and $\mathrm{TN}$ were calculated.

Separation of loosely (epiphytic) and closely associated (putative endophytic) microorganisms. Between 2.2 and $5.3 \mathrm{~g}$ of the moss material pre-treated as described above was thawed and amended with extraction buffer containing ultrapure DEPC water (AppliChem), $0.85 \% \mathrm{NaCl}$ (Merck), and 0.01\% Tween 20 (AppliChem) in a ratio 2:1 (weight percent), a modification of a previously published protocol ${ }^{38}$. The mixture was shaken horizontally for $1 \mathrm{~h}$ at $4{ }^{\circ} \mathrm{C}$ prior to ultrasonication (Bandelin Sonoplus HD3100) with pulsation for $2 \mathrm{~min}\left(1 \mathrm{~s}\right.$ off, $2 \mathrm{~s}$ on) at $0.45 \mathrm{~W} / \mathrm{mL}^{39}$. Extraction buffer containing the epiphytes was filtered through a $0.2 \mu \mathrm{m}$ cellulose filter (Sartorius Stedium). The remaining moss was surface-sterilized with $0.15 \% \mathrm{NaOCl}$ (Roth) for $1 \mathrm{~min}$, and rinsed 7 times with DEPC water according to a modified protocol ${ }^{40}$. Filters and sterilized mosses were ground to powder under sterile conditions with liquid nitrogen, transferred to lysis tubes and stored at $-20{ }^{\circ} \mathrm{C}$ until DNA extraction. For each moss sample, one filter with wash-off (epiphytes) and two technical replicates of the surface-sterilized moss (putative endophytes) were used for DNA extraction and sequencing (below).

DNA extraction and sequencing. Genomic DNA was extracted from $0.4-0.8 \mathrm{~g}$ of each of the surface treated mosses, the filters containing the wash-off as described above, and from about $0.4-0.8 \mathrm{~g}$ untreated sedges and sediment samples as references for the moss samples following the CTAB/phenol-chloroform-based method of ${ }^{41}$. DNA concentrations were quantified with a Nanophotometer P360 (Implen GmbH, München, DE) and a Qubit 2.0 Fluorometer (Thermo Fisher Scientific, Darmstadt, Germany) according to the manufacturer's protocols. Bacterial 16S rRNA genes were amplified with the primer combination S-D-Bact-0341-aS-17 and S-D-Bact-0785-a-A-21 ${ }^{42}$ and archaeal 16 S rRNA genes were amplified with the primer combination S-D-Arch-0349-a-S-17 and S-D-Arch-0786-a-A-20 ${ }^{43}$. The primers were labelled with different combinations of barcodes listed together with primer sequences in table S1B. The PCR mix contained $1 \times$ PCR buffer (Tris. $\mathrm{Cl}$, $\mathrm{KCl},\left(\mathrm{NH}_{4}\right)_{2} \mathrm{SO}_{4}, 15 \mathrm{mM} \mathrm{MgCl}$; $\mathrm{pH}$ 8.7) (QIAGEN, Hilden, Germany), $0.5 \mu \mathrm{M}$ of each primer (Biomers, Ulm, Germany), $0.2 \mathrm{mM}$ of each deoxynucleoside (Thermo Fisher Scientific, Darmstadt, Germany), and $0.025 \mathrm{U}^{-1}$ hot start polymerase (QIAGEN, Hilden, Germany). The thermocycler conditions were $95^{\circ} \mathrm{C}$ for 5 min (denaturation), followed by 40 cycles of $95^{\circ} \mathrm{C}$ for $1 \mathrm{~min}$ (denaturation), $56^{\circ} \mathrm{C}$ for $45 \mathrm{~s}$ (annealing) and $72{ }^{\circ} \mathrm{C}$ for $1 \mathrm{~min}$ and $30 \mathrm{~s}$ (elongation), concluded with a final elongation step at $72^{\circ} \mathrm{C}$ for $10 \mathrm{~min}$. PCR products were purified with a Hi Yield Gel/PCR DNA fragment extraction kit (Süd-Laborbedarf, Gauting, Germany) according to the manufacturer's protocol. PCR products of three individual runs per sample were combined. For sequencing, PCR products of different samples were pooled in equimolar concentrations and compressed to a final volume of $10 \mu \mathrm{L}$ with a concentration of $200 \mathrm{ng} / \mu \mathrm{L}$ in a vacuum centrifuge Concentrator Plus (Eppendorf, Hamburg, Germany). The library preparation and sequencing was performed on an Illumina MiSeq sequencer by the company GATC (Konstanz, Germany) according to their standard protocols. In short, the library was prepared with the MiSeq Reagent Kit V3 for $2 \times 300$ bp paired-end reads. To account for the low-diversity amplicon sampling, we used $15 \%$ PhiX control v3 library.

Sequence analyses and bioinformatics. Raw data was demultiplexed using CutAdapt ${ }^{44}$; e $0.1 ;-$ trim-n; no error in barcodes allowed. Paired-reads were merged using $\operatorname{PEAR}^{45}\left(\mathrm{Q} 25 ; \mathrm{p} 10^{\wedge}-4 ; \mathrm{v} 20\right)$ and sequence orientation was standardized using own scripts. Low quality sequences were filtered and trimmed using Trimmomatic ${ }^{46}$ (LEADING:25; TRAILING:25; SLIDINGWINDOW:5:25; MINLEN:200). Chimeras were removed according to the QIIME SOP ${ }^{47}$. Finally, reads were clustered into Operational Taxonomic Units (OTUs) using QIIME's 
pick_open_reference.py script with a cutoff value of $97 \%{ }^{47}$. Representative sequences of the clusters were annotated with usearch utilizing the curated Greengenes 13.8 taxonomy database ${ }^{48}$. OTUs assigned to chloroplasts, bacterial OTUs within archaeal samples and vice versa, and OTUs with a small, sample-wise relative abundance $(<0.01 \%)$ were filtered before further exploration.

Statistical analyses. Differences in microbial community composition between the sites were obtained by calculating the inverse Simpson index and counting the number of OTUs, as measures of the OTU diversity and richness, respectively. Bubbleplots for Figs. 5 and 6 were generated using the package 'ggplot2' (version 2.2.0) within the statistical software R (version 3.2.2) ${ }^{49}$. Correlation matrices of samples (16S rRNA gene datasets of either bacteria or archaea) were generated using the R function 'cor', specifying the Spearman rank correlation coefficient. Hierarchical clustering of the samples based on the correlation matrices to generate dendrograms were calculated using the method 'agnes' within the R package 'cluster', with default settings. All heatmaps were created using the R package 'heatmap3' (version 0.3.3). The inverse Simpson index diversity estimates for bacteria were calculated using the R package 'asbio' (version 1.6-5). Pairwise t-tests were used for environmental variables and carried out using the R function 'pairwise.t.test'. Pairwise Mann-Whitney-Wilcoxon tests were used for diversity indices and carried out using the R function 'pairwise.wilcox.test'. Canonical correspondence analysis (CCA) was carried out to quantify the explanatory power of biotic and environmental variables with respect to the microbial ecology of the peatlands (package: vegan (version 2.2.1)). Correspondence analysis (CA) was carried out as described in ${ }^{50}$ and plotted using 'ggplot2'. Eight variables; cation exchange capacity, ligninlike polymers, hemicellulose, total nitrogen, total carbon and C:N ratio, DOC, oxygen and water content were removed from the initial full model due to lacking observations for between 23 and $45 \%$ of the samples. We constrained the variation in the microbial communities to the remaining variables; (1) sites (SV, SA, MUE and NEI), (2) subsite (e.g., KIE1), (3) plant species or reference sediment, (4) location above or below water table, (5) washed and surface-sterilized moss plant (putative endophytes) or wash-off (epiphytes) (6) pH, (7) methane concentration in pore water, and 8) temperature. In order to estimate and account for the spatial autocorrelation that the sites (1) and subsite (2) variables represent, we introduced partial CCA. Running the model without (1) and (2) we observed that the constrained inertia was reduced from $72 \%$ of total inertia to $40 \%$. Subsequent analysis of variance inflation factors showed that no remaining variables were redundant. Core communities were calculated with a restrictive $66 \%$ threshold, meaning that an OTU has to be present in 80 out of 122 samples and in both system types (Amblystegiaceae and Sphagnum) for it to be considered part of the core microbiota. Moss system core communities (Amblystegiaceae or Sphagnum) were calculated with the same threshold, $66 \%$. Moss species communities were calculated with a more restrictive threshold of $75 \%{ }^{30}$.

\section{Results}

Peatland characteristics. The sites Svalbard (SV) and Samoylov (SA) contained only mosses of the family Amblystegiaceae and represented minerotrophic fens at the earliest stages of peat formation ('terrestrialisation'), with sub-neutral to neutral $\mathrm{pH}$ values ranging from 5.8-7.0. The sites Neiden (NEI) and Mueritz (MUE), dominated by the genus Sphagnum, represented later stages of peat formation, ('paludification') spanning minerotrophic and nearly ombrotrophic bogs with acidic $\mathrm{pH}$ values ranging from 3.3-5.0, thus significantly lower than in SV and SA (Fig. 2A). DOC values were significantly higher in Sphagnum than in Amblystegiaceae peatlands, with the highest concentrations observed in MUE (42.7-229 mg/L) and lowest in SV (0.9-6.4 mg/L) (Fig. 2B). Also methane concentrations were significantly higher in the Sphagnum than in Amblystegiaceae ecosystems, with the highest range of concentrations in MUE $(21.8-948 \mu \mathrm{M})$ and the lowest in SV $(0-124 \mu \mathrm{M})($ Fig. $2 \mathrm{C})$. The mean soil temperature at the time of sampling was highest in MUE $\left(16.0^{\circ} \mathrm{C}\right.$, range $\left.14.5-17.6\right)$, followed by SA (13.0 ${ }^{\circ} \mathrm{C}$, range $\left.4.0-19.5\right)$, NEI $\left(12.6^{\circ} \mathrm{C}\right.$, range $\left.2.0-20.7^{\circ} \mathrm{C}\right)$ and $\mathrm{SV}\left(9.8^{\circ} \mathrm{C}\right.$, range $\left.7.1-12.1^{\circ} \mathrm{C}\right)(\mathrm{Fig} .2 \mathrm{D})$.

Diversity and structure of natural peatland microbial communities. We obtained between 2510 and 289,604 sequences (average of 78,933, median of 68,070 and std.dev. of 60,092) for the 122 bacterial datasets and between 536 and 83,642 (average 12,626, median of 4892 and std.dev. of 17,424) sequences for the 86 archaeal datasets. Consequently, of the 157 samples collected we were unable to generate 16S rRNA gene amplicon libraries from 35 samples with bacterial primers and 71 samples with archaeal primers either because PCR gave no product or sequencing failed. There was a significantly higher bacterial diversity and OTU richness in the moss and reference samples from Amblystegiaceae-dominated SV and SA sites compared to the Sphagnumdominated NEI and MUE sites (Fig. S1). Interestingly, the microbial communities in the Amblystegiaceae sites displayed the same level of diversity, independent of the geographical location. This also applied to the Sphagnum sites. Unlike the bacterial diversity, the archaeal diversity was similar between the Amblystegiaceae and Sphagnum peatlands with overall little differences between mosses, sediments and vascular plants (Fig. S2). An exception was that the sediments in the Amblystegiaceae sites displayed slightly higher archaeal richness than the other sites.

To identify the association between moss taxa, abiotic environmental variables and the bacterial moss microbiota, we performed a canonical correspondence analysis (CCA). Using variance partitioning we quantified the contribution of the variables to the explanation of total inertia in the following order from most to least important: (1) plant species and reference sediment: $19.7 \%$ (p. value $<0.001$ ), (2) temperature: $4.8 \%$ (p. value $<0.001$ ), (3) putative endophytes or epiphytes: $4.6 \%$ (p. value $<0.001$ ), (4) methane concentration in pore water: $4.1 \%$ (p. value $<0.001$ ), (5) pH: $3.3 \%$ (p. value $<0.001$ ) (6) location above or below water table: $3.2 \%$ (p. value $<0.001$ ). Repeating the procedure with Hellinger transformed data to control for large effects of low abundant OTUs we observed the same patterns at highly similar total and constrained inertia, suggesting that the impact of rare OTUs on CCA ordination was minor. Initially, our model included sites and subsites in addition to the six above 
A

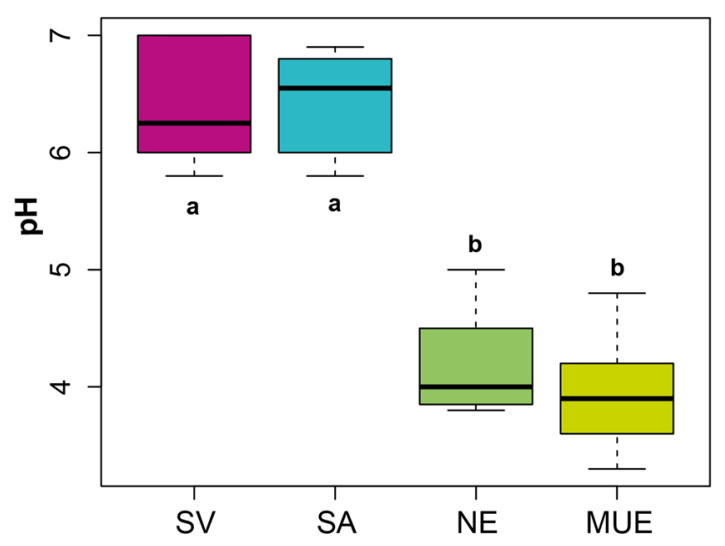

C

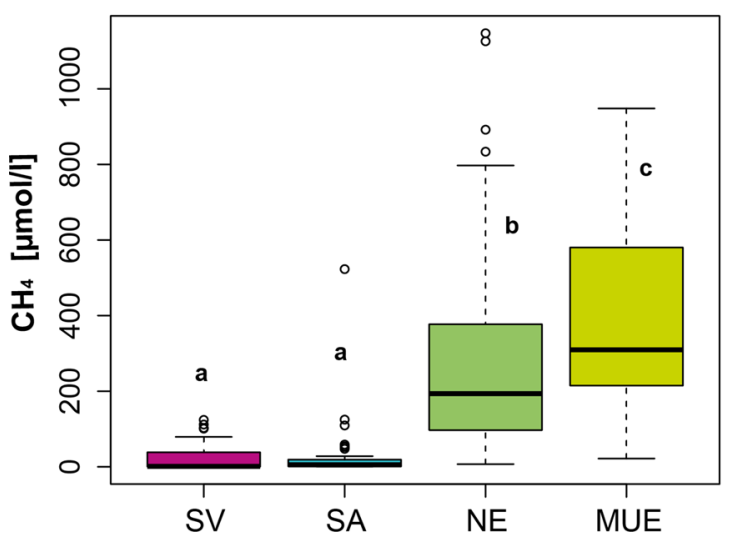

B

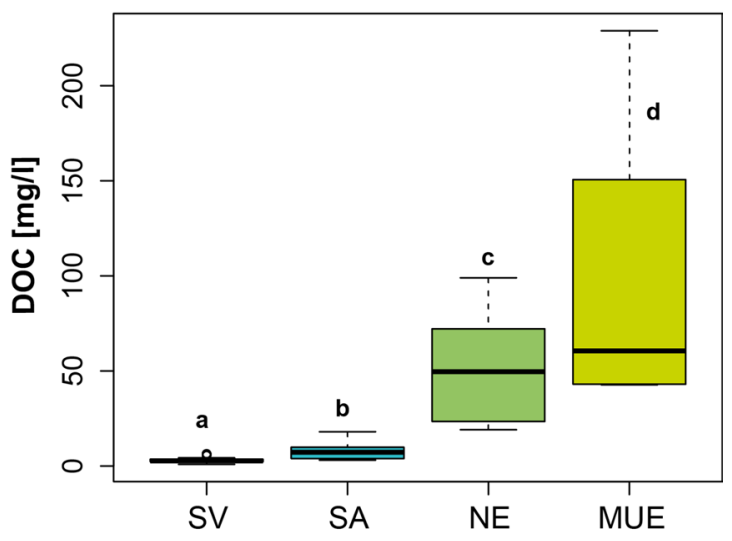

D

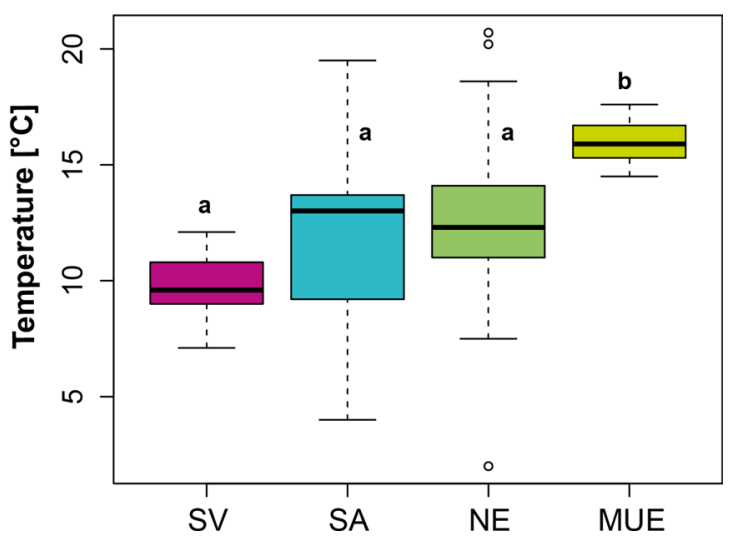

Figure 2. Box plots showing the measurements of selected environmental variables. (A) $\mathrm{pH}$, (B) dissolved organic carbon (DOC), (C) methane and (D) temperature of all subsites in Svalbard (SV, magenta), Samoylov (SA, blue), Neiden (NEI, dark green) and Mueritz (MUE, light green). Pairwise t-tests suggest that samples with different letters show a significant $(\mathrm{p}<0.05)$ difference in the mean value between each other.

mentioned variables, together accounting for $32 \%$ of the differences between the microbial communities (see materials and methods). As site effects and plant species effects correlate, it is likely that by removing site effects we have substantially underestimated the plant species influence. The removed fraction of the inertia contained in the site variables we consider the 'environment', a mix of abiotic and biotic variables that cannot be studied in isolation with our dataset.

Due to its complexity, we were unable to visualize the major gradients in the dataset using a single CCA plot. Thus, we plotted the constraints of the final model above separately (Fig. 3). The plots show that substantial parts of the bacterial communities correlate with the moss or vascular plant species (Fig. 3A) and by being submerged in water or above (Fig. 3F). At one instance we saw that the water table had a stronger impact on the microbiota than the plant species; the $S$. fallax samples closest to the S. riparium in Fig. 3 A were submerged, as were all the $S$. riparium samples. There were also consistent differences between endophytic and epiphytic communities (Fig. 3C). Furthermore, in line with the differences in $\mathrm{pH}$ and temperature, we observed clear differences between the Amblystegiaceae and Sphagnum bacterial communities (Fig. 3B,E), while the effects of altered methane concentrations on the microbial communities were similar in Amblystegiaceae and Sphagnum ecosystems (Fig. 3D). The CCA explained approximately $40 \%$ of the variance in the dataset. The small explained variance was to a large extent due to the removal of area and subsite variables which was not considered explanatory variables.

To allow an evaluation of this area and site-dependent structure of the microbial communities we constructed a Spearman correlation based dendrogram of the OTU profiles, along with some of the categorical variables. The analysis revealed a very high level of agglomerative clustering in the dataset (0.86), particularly considering the large size of the dataset. The resulting dendrogram confirmed some of the previously observed patterns, such as the differences associated with dominating moss vegetation (Amblystegiaceae or Sphagnum) and hydrology (Fig. 4). However, it also revealed additional data structures. Starting from the top of Fig. 4, we can see the 

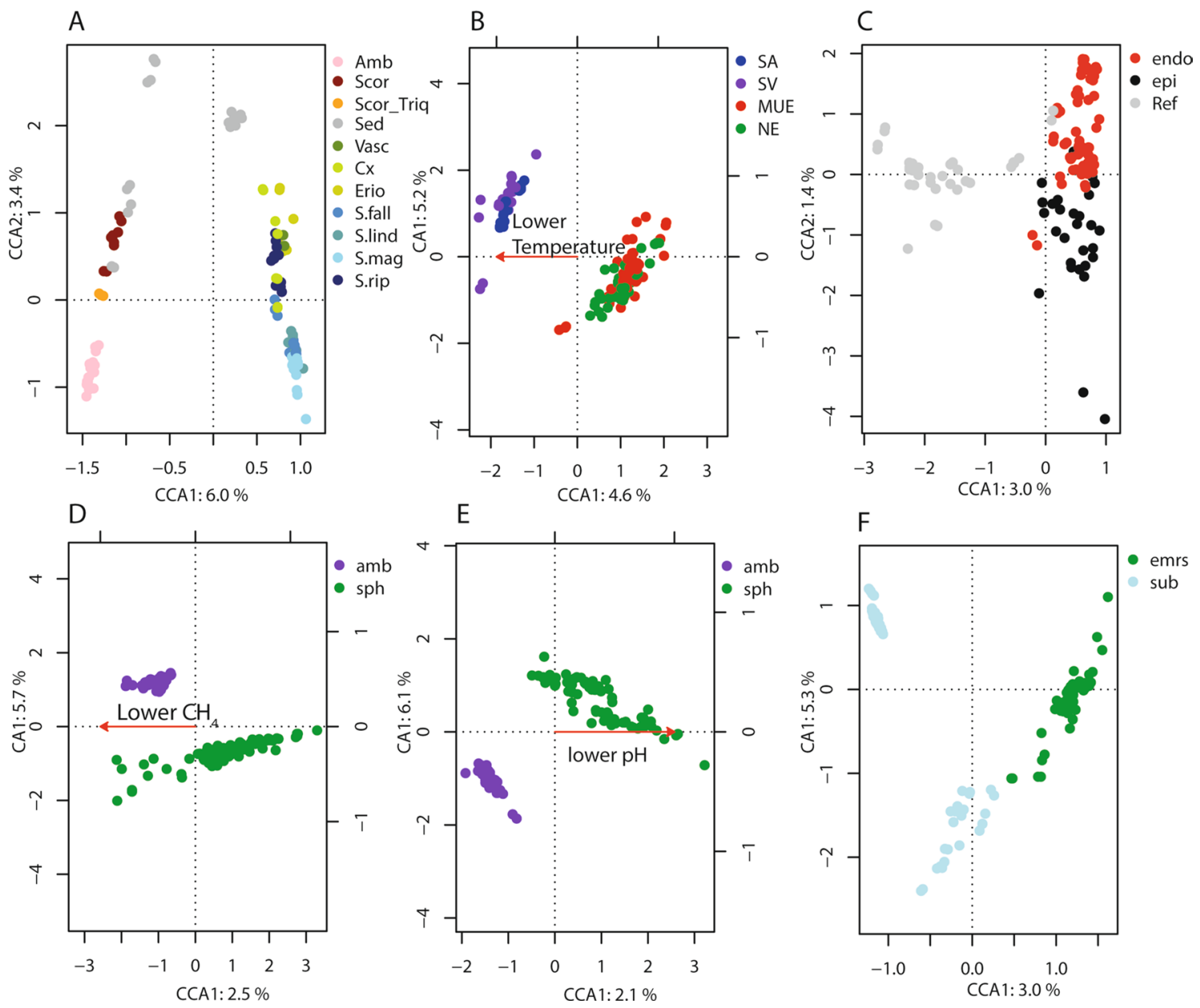

Figure 3. Canonical correspondence analysis of moss-associated bacterial OTUs. The axes represent the first and second CCA dimension in the case of categorical variables with more than two factors $(\mathbf{A}, \mathbf{C})$. In the case of 2 factors or continuous variables (B,D,E,F) the first CA dimension is showed on the Y-axis, while the CCA dimension is showed on the $\mathrm{X}$-axis. (A) Constrained by plant species and reference sediment; Amb: Amblystegiaceae mix; Cx: Carex; Erio: Eriophorum; S.fall: Sphagnum fallax; S.lind: Sphagnum lindbergii; S.mag: Sphagnum magellanicum; S.rip: Sphagnum riparium; Scor: Scorpidium scorpioides; Scor_Triq: Mix of Scorpidium scorpioides and Meesia triquetra; Sed: Sediment; Vasc; Mix of Vascular plants. (B) Constrained by location above or below the water table; emrs: Above the water table; sub: below the water table. (C) Constrained by being from the washed moss plant (putative endophytic: endo), wash-off (putative epiphytic: epi) or from reference sample (Ref). (D) Constrained by pH, samples coloured by System; amb: Amblystegiaceae; sph: Sphagnum. (E) Constrained by temperature, samples coloured by Area; MUE Mueritz; NEI Neiden; SA Samoylov; SV Svalbard. (F) Constrained by $\mathrm{CH}_{4}$ concentration in pore water, samples colored by System; amb Amblystegiaceae; sph Sphagnum.

bacterial communities split by (1) the overall system and moss type, Amblystegiaceae or Sphagnum-dominated. (2) With few exceptions the bacterial communities within the two systems split by areas. (3) In almost all cases, the communities from the same subsites clustered together. (4) Within each subsite, the epiphytic communities clustered separately from the endophytic communities, but consistently the endophytic and epiphytic libraries from the same plant clustered together. (5) The submerged NEI and MUE moss communities clustered together. (6) Within the Sphagnum system, most of the vascular plant communities clustered together with the sediment and submerged moss communities.

Amblystegiaceae- and Sphagnum-associated microbial taxa. To identify which bacterial and archaeal groups accounted for the majority of microbial community variation we studied the communities at family level. Within bacteria, we observed an evenly high abundance of families in the Amblystegiaceae moss microbiota; Acidimicrobiales_C111, Pseudoanabaenaceae, Hyphomicrobiaceae, Sphingomonadaceae and Comamonadaceae (Fig. 5).

In contrast, only two bacterial families dominated the Sphagnum moss microbiota; Acetobacteraceae and Acidobacteriaceae. Sphingomonadaceae was the only family present at similar relative abundances in the Amblystegiaceae and Sphagnum systems. To identify the nature of these large differences we studied the OTU composition of Acetobacteraceae in more detail (Fig. S3). The relative abundance of Acetobacteraceae was higher in 


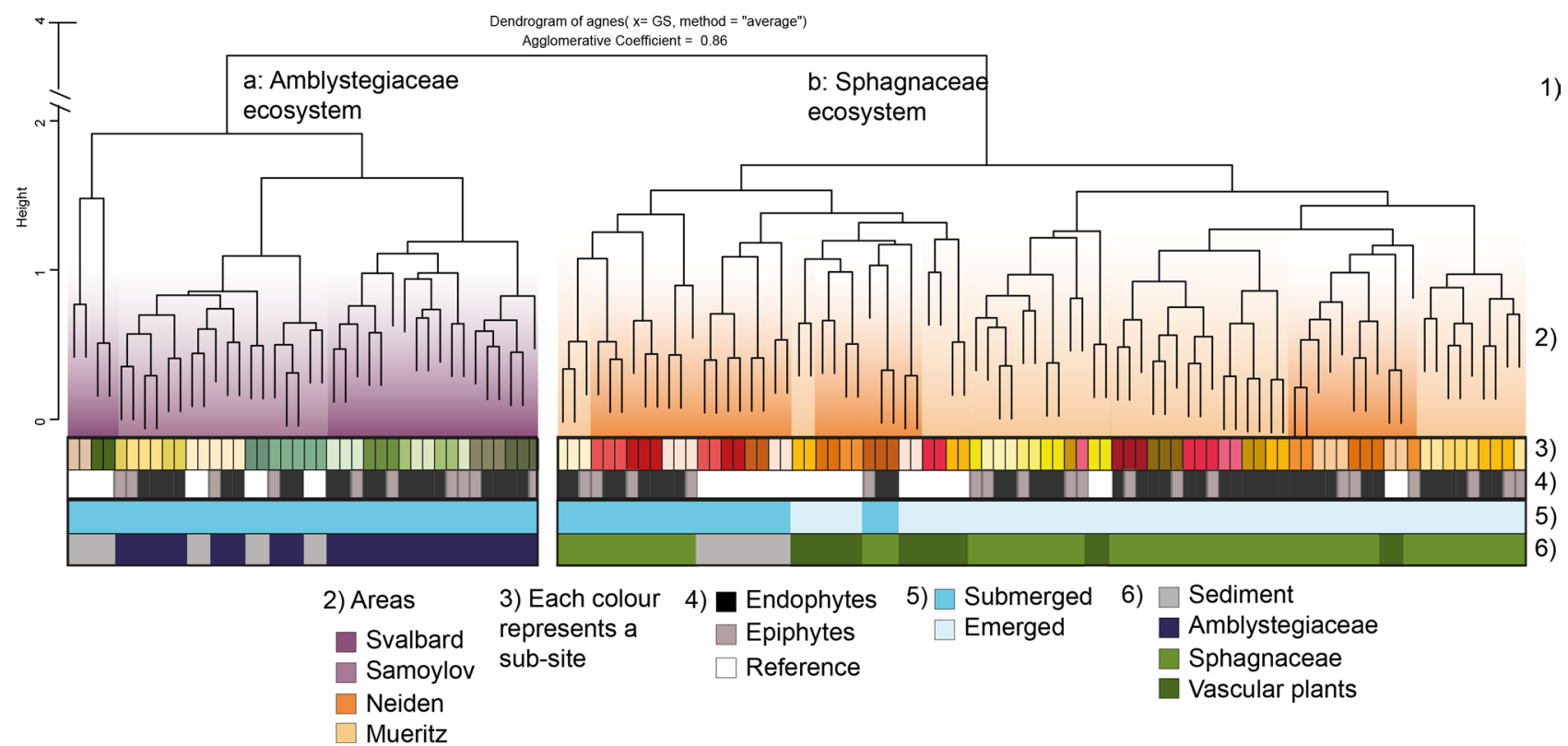

Figure 4. Dendrogram showing the clustering of bacterial communities (OTU at $97 \%$ sequence similarity) in relation to the environmental and biotic characteristics of the sites. Each tip of the dendrogram corresponds to the community profile of a moss, vascular plant or sediment sample. All possible pairwise spearman correlation factors were calculated from the community profiles and the resulting distance matrix used to cluster the samples applying the agnes hierarchical clustering algorithm. Numbers refer to different levels of clustering. The first level of clustering, (1), shows that the samples from ecosystems dominated by Amblystegiaceae and the samples from ecosystems dominated by Sphagnaceae end up in two different clusters. The second level of clustering, (2), shows that the majority of samples from the same sites cluster together, but that exceptions related to hydrology and reference samples occur. Level (3) shows that bacterial communities from the same subsite almost exclusively cluster together. Level (4) show that the putative endophyte amplicon libraries from the washed moss plant almost always cluster with the wash-off library containing the putative epiphytic library from the same moss plant. Level (5) show a clear microbial community separation by the hydrology of the site. Level (6) show some clustering based on whether the community is from a vascular plant, sediment or moss.

Sphagnum than in Amblystegiaceae systems and the majority of Acetobacteraceae OTUs were present only in Sphagnum. However, some OTUs were only present in Amblystegiaceae, while a handful of OTUs were present in both the Amblystegiaceae and Sphagnum peatlands. To identify whether this distinctly different OTU composition with few overlaps was a general pattern, we repeated the analysis for other major bacterial taxa. The same pattern was observed for Acidobacteria (Fig. S4), Acidimicrobiales (Fig. S5), and Cyanobacteria (Fig. S6). This points towards distinct bacterial communities of Sphagnum- and Amblystegiaceae-dominated peatlands, while only individual OTUs occurred in both peatland types. Among the community of methane oxidizing bacteria (MOB), Methylocystis was most abundant (Fig. S7). Unlike most bacterial taxa, Methylocystis occurred in almost all of the sites but its relative abundance varied and correlated positively with the amount of methane in the pore water. In addition to Methylocystis, the MOB community contained members of within Methylomonas. In contrast to Methylocystis, OTUs affiliated with Methylomonas occurred primarily in Sphagnum sites, preferentially under submerged conditions. Finally, Methyloferula-associated OTUs were also detected among MOB but at low relative abundances. These OTUs were restricted to emerged Sphagnum sites. The fasta files of methanotrophic OTUs in Fig. S7 is provided as additional supplement (S_methanotrophs_fasta). The complete OTU table for bacteria is provided as supplementary information (Supplement_Bacteria_OTU_table).

Clustering of the archaeal communities did not reveal any hierarchical clustering patterns related to sample origin (Fig. S8), as was observed for bacteria. The OTUs within the phylum Euryarchaeota, the majority of which belonged to families/genera of methanogenic archaea, dominated the archaeal communities (Fig. 6).

The most abundant OTU belonged to the hydrogenotrophic methanogenic family Methanobacteriaceae. This OTU was present in almost all the samples of both Amblystegiaceae and Sphagnum ecosystems (Fig. S9). Furthermore, Methanomassiliicoccaceae, Methanocellales, and Methanosarcinaceae were widespread while Methanosaetaceae occurred mainly in the Amblystegiaceae sites. Outside the phylum of Euryarchaeota, the Bathyarchaeota were abundant throughout most of the sites while Woesearchaeota mainly occurred in the Amblystegiaceae sites. The complete OTU table for archaea is provided as supplementary information (Supplement_Archaea_OTU_table).

The core and moss-associated microbiota. Only about $0.4 \%$ of all bacterial OTUs identified (49 out of 13,799) were observed in both Sphagnum and Amblystegiaceae ecosystems and were designated as the core microbiome (see materials and methods for definition of core microbiome). The majority of these OTUs belonged to Acetobacteraceae and Acidobacteriaceae, the dominating bacterial families of the Sphagnum micro- 


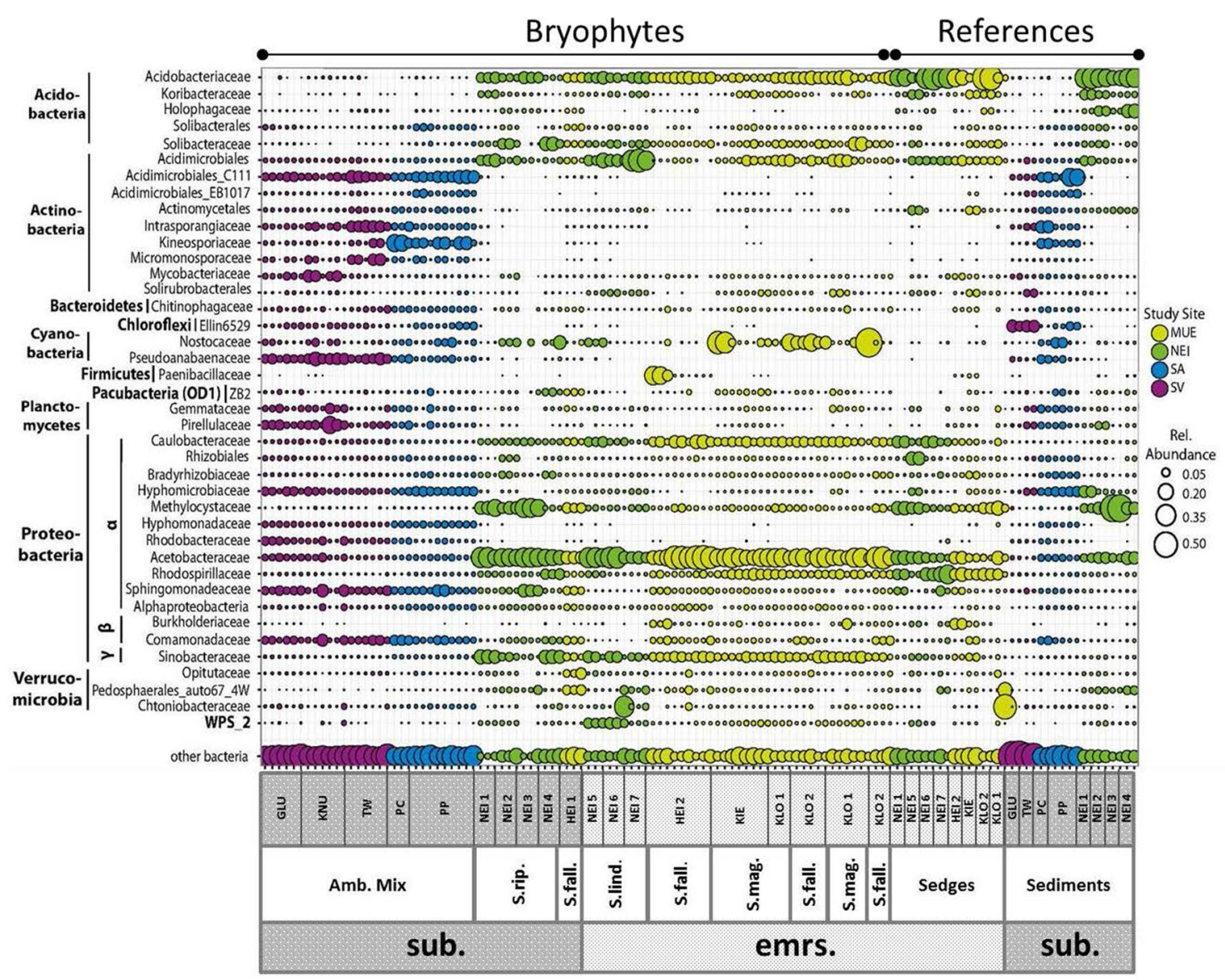

Figure 5. Overview of the relative abundances of bacterial families making up more than $0.5 \%$ of the total bacterial sequences in one or more $16 \mathrm{~S}$ rRNA gene libraries. The sizes of the circles correspond to the relative abundances of the families. The colors indicate which region the samples originate from. MUE: Mueritz, Northern Germany (light green); NEI Neiden, Northern Norway (dark green); SA Samoylov, Russia (blue); $S V$ Svalbard, Norway (violet). The samples are sorted by ecosystem types and latitude from left to right. sub. = submerged. emrs. = emerged/above the water table. Amb. Mix. = a mix of Amblystegiaceae. S. rip. $=$ Sphagnum riparium. S. fall. $=$ Sphagnum fallax. S. mag $=$ Sphagnum magellanicum. S. Lind. $=$ Sphagnum lindbergii.

biota. These 49 OTUs (52 if only considering mosses) contributed $1-9 \%$ of the total OTU abundance in Amblystegiaceae ecosystem and $12-65 \%$ in Sphagnum ecosystem, showing that the OTUs present in both systems are among the most abundant OTUs in Sphagnum sites (Table S2A). Further, we addressed whether the core microbiome of all mosses was similar in size to the individual bacterial core microbiome of Amblystegiaceae and Sphagnum mosses (moss system core communities), respectively. We found that by applying the same threshold as for the total core microbiome (TCM), the Amblystegiaceae core microbiome (ACM) was 348 OTUs, while the Sphagnum core microbiome (SCM) was 142 OTUs (Table S2A). Out of these, 20 were shared between TCM and ACM, while 46 were shared between TCM and SCM. To identify whether specific moss types shared larger core microbiomes, we calculated the moss species communities of the Amblystegiaceae mosses from Svalbard, the Amblystegiaceae mosses of Samoylov (only Scorpidium), Sphagnum riparium, S. fallax, S. lindbergii and $S$. magellanicum, respectively (Table S2B). This showed that the individual core microbiomes are in a similar size range as for the broader core microbiomes at 295, 548, 126, 132, 252 and 154 OTUs, respectively. Calculating the intersects of these core microbiomes we found that the Sphagnum mosses share a larger proportion of their core microbiomes with each other than with the Amblystegiaceae mosses (Table S2C). Interestingly, Scorpidium mosses shared more OTUs with the Sphagnum species than Amblystegiaceae mosses from Svalbard shared with Sphagnum mosses. The Svalbard and Samoylov mosses shared the highest number of OTUs, reflecting the larger overall number of OTUs associated to these mosses and their larger core microbiomes. Consistently for all core microbiomes calculated, the relatively few OTUs compared to the total number of OTUs identified accounted for a large proportion of the relative abundance in the microbial communities.

Next we sought to identify the dominant endophytic communities of Amblystegiaceae and Sphagnum mosses. Thus, we plotted the most abundant OTUs of significantly higher abundance in endophytic than epiphytic communities. This showed that almost none of the most abundant putative endophytes (washed and surface sterilized moss samples) of Amblystegiaceae were shared with Sphagnum (Fig. 7).

The taxonomic assignment and list of fasta files for the putative endophytes is provided as supplementary material (S_endophytes_taxonomy; S_endophytes_fasta). The Sphagnum endophytes belonged to several families 


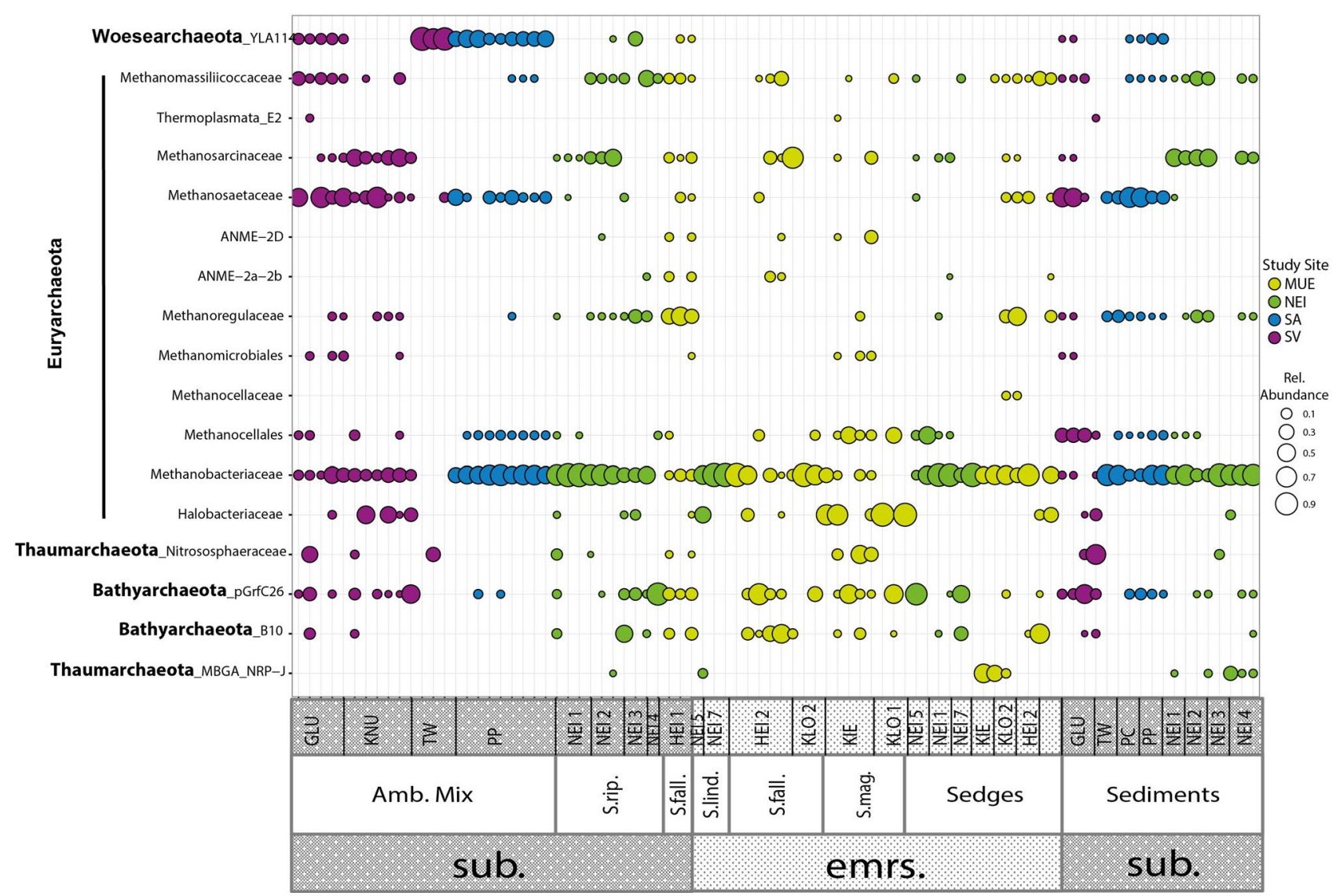

Figure 6. Overview of the relative abundances of archaeal families making up more than $0.5 \%$ of the total archaeal sequences in one or more 16S rRNA gene libraries. The sizes of the circles correspond to the relative abundances of the families. The colors indicate which region the samples originate from. MUE Mueritz national park; NEI Neiden, Northern Norway; SA Samoylov, Siberia; SV Svalbard, Norway. The samples are sorted by ecosystem types and latitude from left to right. sub. = submerged. emrs. = emerged/above the water table. Amb. Mix. = a mix of Amblystegiaceae. S. rip. =Sphagnum riparium. S. fall. = Sphagnum fallax. S. mag =Sphagnum magellanicum. S. lind. = Sphagnum lindbergii.

within Proteobacteria and Acidobacteria, while the Amblystegiaceae endophytes belonged to Actinobacteria, Proteobacteria, Chloroflexi, Firmicutes and Gemmatimonadetes. Interestingly, of the 24 most abundant Sphagnum endophyte OTUs, 19 were observed in the total core microbiome. Thus these are primarily epiphytes of Amblystegiaceae.

\section{Discussion}

We studied the relationship between the moss-associated microbial communities and their respective moss taxa and physico-chemical environments in four sites, in which two were analogous to early (mosses of the family Amblystegiaceae) and two to later (mosses of the genus Sphagnum) successional stages of natural northern peatlands. We identified both biotic and abiotic controls on the microbial community structure and distinctly different communities in the Amblystegiaceae and Sphagnum mosses. The core community consisted of few but highly abundant members of the microbial community, of which many were endophytes of Sphagnum.

Biotic and environmental drivers of moss-associated bacterial communities. Our study approach allowed ranking the influence of individual variables on microbial community structure relative to the combined dataset. Given that the sum of individual variables reduced the explanatory power by almost $50 \%$ compared to the combined dataset that included also area and subsites, and also considering the hierarchical clustering in the bacterial dendrogram, we conclude that a large set of biotic and environmental variables correlate with the ecosystem type, Sphagnum- or Amblystegiaceae-dominated peatlands, and that the sum of these exert a major influence on the bacterial community structure. This is in accordance with other studies where soil bacterial communities were reported to structure according to ecosystems $\mathrm{s}^{51}$ and characteristic microbial communities which evolved in contrasting peatland ecosystems that differed mainly in vegetation, water chemistry and hydrology ${ }^{52,53}$. Sphagnum versus brown moss cover was also suggested as the major factor determining diversity and assemblages of testate amoebae ${ }^{54}$. Not only did the peatland ecosystem shape bacterial community structure, but also species richness and diversity, which was significantly higher in sub-neutral Amblystegiaceae compared to acidic Sphagnum peatlands, corresponding to findings from neutral compared to acidic 


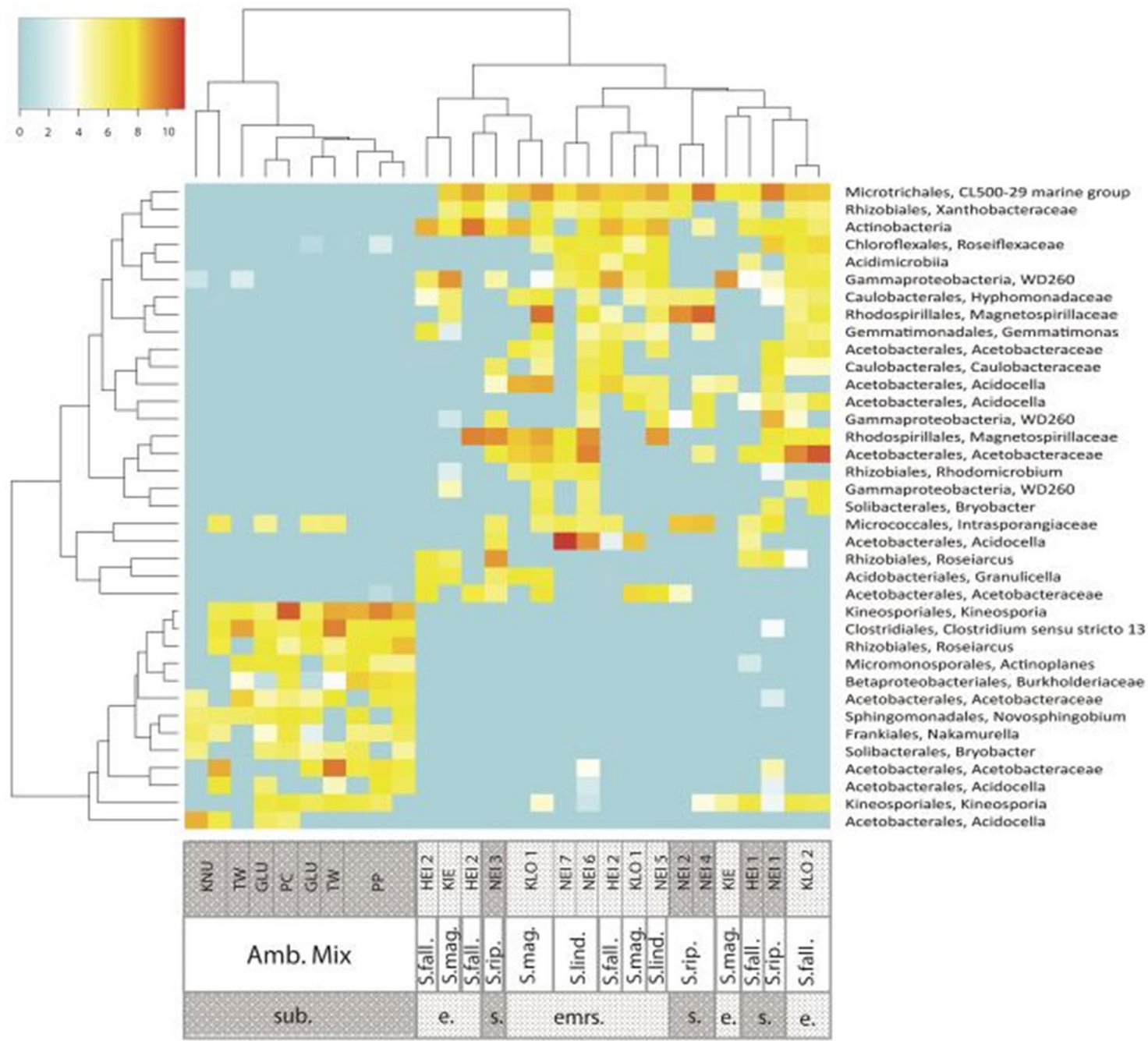

Figure 7. Heatmap displaying the most abundant OTUs present at significantly higher abundance in putative endophytic than epiphytic libraries of the same sample. Chi-square contingency table tests were applied, where the p-values were calculated for Monte Carlo simulations with 5,000 replicates. The significance threshold was set at 0.001 . Of the OTUs present at significantly higher abundance in the putative endophytic than epiphytic libraries, only OTUs at a higher than $0.5 \%$ relative abundance (average of the two endophytic libraries of each sample) in four or more samples were plotted in the heat map. The color intensity corresponds to the binary logarithm of the average relative abundance of the OTU in the two endophytic libraries multiplied by 100,000 . Pearson correlation was used as the basis for the hierarchical clustering of samples and OTUs in the heatmap. sub. $=$ submerged. emrs. $=$ emerged/above the water table. Amb. Mix. $=$ a mix of Amblystegiaceae. S. rip. = Sphagnum riparium . S. fall. = Sphagnum fallax. S. mag = Sphagnum magellanicum. . Lind. =Sphagnum lindbergii. Bacterial communities of brown moss samples from Twin water (TW), Gludneset (GLU) and Knudsenheia (KNU) in Svalbard and from polygonal crack (PC) and polygonal pond (PP) in Samoylov. Bacterial communities of Sphagnum samples from Klockenbruch (KLO), Kiebitzmoor (KIE), Heidbergmoor (HEI) in Germany, and Neiden (NEI) in Northern Norway.

soil environments ${ }^{51,55}$. Presumably, most bacteria lack substantial mechanisms to regulate their intracellular $\mathrm{pH}$ close to neutral when exposed to low extracellular $\mathrm{pH}$ and thus are not able to survive under acidic conditions $\mathrm{s}^{56}$. Contrarily, most bacteria adapted to low $\mathrm{pH}$ can survive at neutral $\mathrm{pH}$, possibly explaining the occurrence of Acidobacteriaceae and Acetobacteraceae in all samples studied, but in much higher abundances in sites with low $\mathrm{pH}$. Acetobacteraceae and Acidobacteriaceae were previously reported to be among the dominant Sphagnumassociated microbial groups ${ }^{31,57,58}$ and generally thrive in low $\mathrm{pH}$ habitats ${ }^{59,60}$.

Among the individual variables, the specific plant taxa explained four to five times more of the observed inertia than any of the other controlling variables such as temperature, hydrology, and $\mathrm{pH}$. This essentially shows that the different plants harbor their own microbiome which is similar to that of closely related plants. Differences in bacterial communities between different Sphagnum species were shown previously ${ }^{27,31,32}$. Our findings extend this knowledge on the influence of the host plant on bacterial community structure to other Sphagnum species such as S. riparium and S. lindbergii, to Scorpidium scorpioides, a member of the Amblystegiaceae, and also to some vascular peatland plants like Carex and Eriophorum. It further supports that although the sediment 
microbiome does correspond with the different dominant species, it is distinct from that associated with plants as indicated before ${ }^{61}$.

The relationship between temperature and microbial community structure accounted for only $4.8 \%$ of inertia in the partial CCA although the investigated mosses were located in different climatic zones. Here, temperature is based on a point measurement and thus not necessarily expected to be representative of growing season average temperatures. Still, a poor influence of temperature on bacterial assemblages both on short and long time-scales is in line with other studies ${ }^{62,63}$. Hydrology was identified as another variable that affects moss-associated bacterial communities in natural peatlands. In some instances hydrology was more important than the influence of the host plant; emerged and submerged $S$. fallax sampled from the same subsite (HEI) carried different microbial communities while the microbiota of submerged S. fallax (Mueritz, Germany) was more similar to submerged $S$. riparium (Neiden, Norway) than $S$. fallax growing above the water table. This confirms a strong influence of hydrology on host moss morphology and physiology ${ }^{64-66}$ and the associated microbial communities. The influence of the water table on moss-associated microbial community structure and activity was already reported for Sphagnum ${ }^{20,24,67}$ but here we extend it to a larger spatial and environmental scale including Amblystegiaceae. Sphagnum and Amblystegiaceae-associated archaea were dominated by methanogenic Euryarchaeota, Bathyarchaeota and Woesearchaeota. This supports the hypothesis that Woesearchaeota occur in methanogenic environments, possibly as syntrophic partners with methanogens ${ }^{68}$. The role of Bathyarchaeota is unclear, but its presence corresponds to its former observations in peatlands ${ }^{69}$. There was some site-dependent clustering of the archaeal communities, e.g. Methanosaeta was only found in association with the neutral Amblystegiaceae mosses and associated sediments which is consistent with the biogeography of Methanosaetaceae ${ }^{70}$. The most abundant methanogen, belonging to Methanobacterium, was present in all sites and samples, which is also in accordance with the biogeography of Methanobacterium being among the most abundant methanogenic taxa both in $\mathrm{pH}$ neutral and low $\mathrm{pH}$ soils ${ }^{70}$. Similar to the community of methanogens, also the most abundant methane oxidizing OTU belonging to Methylocystis was present throughout all sites corresponding to its prevalence in wetlands ${ }^{71}$. Its abundance correlated with pore water methane concentrations (Fig. S7) which corresponds to related studies ${ }^{72,73}$. It was proposed that historical contingencies (i.e., random events), rather than evolutionary acquired fitness underlie the variations in Methylocystis communities ${ }^{74,75}$. Based on this, we suggest that Methylocystis adapted to the changes associated to succession, including $\mathrm{pH}$. The observation that the communities of methane oxidizers in this study are dominated by Methylocystis, with high abundances of Methylomonas and Methyloferula in the Sphagnum-sites, extends on related studies which showed that Methylobacter typically thrives in Arctic pHneutral peatland soils ${ }^{18,76}$. Together with a number of studies focusing on the cultivation of methane oxidizers in Sphagnum peatlands ${ }^{77-80}$, this study further shows that the vegetation-associated methanotrophic community of Arctic peatlands is different from that of the peat soil (similar to what was discussed earlier for the overall microbiota) and that the low $\mathrm{pH}$ Sphagnum peatlands favor specific methanotrophic taxa such as Methyloferula.

Distinct patterns of endophytic bacteria. We identified distinct patterns of putative endophytic bacteria for both Sphagnum and Amblystegiaceae. The different bacterial endophytes in Amblystegiaceae compared to Sphagnum likely reflect a direct influence of the moss taxa on the microbiota. It was suggested earlier that Sphagnum plants select for beneficial bacteria through secondary metabolites ${ }^{32}$. The cell wall of Sphagnum contains polysaccharides and lignin-like polymers ${ }^{81}$, and our data show that the cell wall composition of Sphagnum and Amblystegiaceae is basically the same (Table S1A). Further, pectin-like polymers represent a minor fraction of cell wall polysaccharides, providing the mosses with substantial cation exchange capacity $(\mathrm{CEC})^{81,82}$ which is similar in both moss groups (Table S1A), corresponding to previous findings ${ }^{13}$. However, Amblystegiaceae have a greater proportion of lignin-like phenolic polymers compared to Sphagnum. Also, in Sphagnum-dominated sites the cation exchange maintains low $\mathrm{pH}$. By contrast, the cation exchange does not reduce and control $\mathrm{pH}$ in Amblystegiaceae-dominated fens due to the substantial neutralization capacity of the mineral-rich groundwater. Besides a direct $\mathrm{pH}$ control, the cation exchange sites of Sphagnum pectin-like polymers inhibit microbial activity when these polymers hydrolyze and are released to the surroundings as so-called sphagnan ${ }^{81}$. Apart from the selection of beneficial microorganisms, Sphagnum protects itself against pathogens, e.g. via close association with antagonistic and antifungal bacteria or by release of antimicrobial substances ${ }^{81-84}$.

We further found that the putative endophytic microbiota was distinct from the epiphytic microbiota. It is known that bacterial endophytes can be host plant-specific promoting growth or health of their hosts ${ }^{85,86}$. Several OTUs, shown here to represent putative endophytes of Sphagnum or Amblystegiaceae, were previously reported as host plant-specific, e.g., Kineosporiaceae, Hyphomicrobiaceae, Intrasporangiaceae and Acidimicrobiales ${ }^{87-90}$. Endophytic microorganisms can be transferred from one generation to another, as shown for Sphagnum, or colonize the host from the surroundings after attraction by moss secreted chemical signals ${ }^{31,40,91}$. The inheritance and selection of potentially beneficial endophytes may provide an explanation for the distinct endophytic communities not only of Sphagnum but also of Amblystegiaceae.

The core microbiota and its possible role for peatland succession. The total core microbiome of Amblystegiaceae and Sphagnum ecosystem samples was small compared to the total number of OTUs identified (49 vs. 13,799). However, the Sphagnum core microbiome in our study (142 OTUs) spanning Subarctic and temperate regions was similar in size to the alpine Sphagnum bog core microbiome (260 OTUs) reported elsewhere ${ }^{30}$. The sum of relative abundances of the OTUs in the total core microbiome was very high. Thus, this core community is a collection of few but highly abundant and thus, presumably, important members of the moss-associated microbial communities. On the other hand, the large numbers of low abundant OTUs that are not part of the core microbiomes identified in this study are possibly a result of local assemblies of microorganisms from the immediate surroundings. Notably, a major part of the total core microbiome were epiphytes on 
Amblystegiaceae, while dominant endophytes in Sphagnum. It needs to be emphasized that the patterns are dominated by the moss samples which reflects the sample design at least to some extent since we mainly collected mosses. Nevertheless, those patterns appear robust since the reference samples associate well with the moss samples (Fig. 4). Considering that these observed patterns of epi- and endophytes are consistent across large distances, many subsites, moss species and conditions, we hypothesize that Sphagnum recruited parts of the Amblystegiaceae microbiome during establishment in Amblystegiaceae peatlands, after which parts of the recruited microbiome adapted and became dominant endophytic members of the Sphagnum core microbiome that can be vertically transferred to the next generation as shown previously ${ }^{31}$. This way, over time, a Sphagnum core microbiome that originated in part from Amblystegiaceae, may have established. Alternatively, recruitment of microorganisms by Sphagnum is independent from peatland succession. If so, the presence of abundant OTUs that are dominant endophytes of Sphagnum and epiphytes of Amblystegiaceae is a coincidence and these bacteria dominate both systems because they are able to survive in both types of environments. However, considering that Amblystegiaceae and Sphagnum co-exist during peatland succession, a frequently occurring event through history ${ }^{9,11,16}$, it is possible that parts of the shared microbiome have transferred during times of co-existence. However, as the existence of an abundant core microbiome was first identified during the analysis of these data, the question of its role during succession is outside the scope of the current study.

\section{Conclusion}

We have uncovered the identity of moss-associated microorganisms in both Sphagnum and Amblystegiaceae peatlands and show that the dominant part of the moss microbiota in northern peatlands is influenced by the plant host. Amblystegiaceae and Sphagnum mosses share a small but highly abundant bacterial core microbiome with members that are dominant endophytes in Sphagnum and epiphytes in Amblystegiaceae. Future work is needed to test whether this core microbiome is a result of transfers of epiphytic bacteria from Amblystegiaceae to Sphagnum during natural peatland succession from fens to bogs.

\section{Data availability}

Demultiplexed read sequence data has been deposited at NCBI/Genbank database under the BioProject PRJNA356121 with accession numbers SRR6442387- SRR6442509 for bacteria and SRR6442615-SRR6442637 for archaea.

Received: 11 May 2020; Accepted: 2 December 2020

Published online: 29 December 2020

\section{References}

1. Chapman, S. et al. Exploitation of northern peatlands and biodiversity maintenance: a conflict between economy and ecology. Front. Ecol. Environ. 1, 525-532 (2003).

2. Joosten, H. Zustand und Perspektiven der Moore weltweit. Nat. Landschaft 87, 50-55 (2012).

3. MacDonald, G. M. et al. Rapid early development of circumarctic peatlands and atmospheric $\mathrm{CH} 4$ and $\mathrm{CO} 2$ variations. Science 314, 285-288 (2006).

4. Freeman, C., Ostle, N. \& Kang, H. An enzymic 'latch' on a global carbon store. Nature 409, 149 (2001).

5. Macdonald, J. A. et al. Methane emission rates from a northern wetland; response to temperature, water table and transport. Atmos. Environ. 32, 3219-3227 (1998).

6. Holden, J. Peatland hydrology and carbon release: why small-scale process matters. Philos. Trans. R. Soc. A 363, 2891-2913 (2005).

7. Joosten, H. \& Clarke, D. Wise Use of Mires and Peatlands. (International Mire Conversation Group and International Peat Society, 2002).

8. Bauer, I. E., Gignac, L. D. \& Vitt, D. H. Development of a peatland complex in boreal western Canada: lateral site expansion and local variability in vegetation succession and long-term peat accumulation. Can. J. Bot. 81, 833-847 (2003).

9. Schumann, M. \& Joosten, H. A Global Peatland Restoration Manual 357-385 (2008).

10. Kuhry, P. \& Turunen, J. The Postglacial Development of Boreal and Subarctic Peatlands. In Boreal Peatland Ecosystems (Springer, New York, 2006).

11. Rydin, H., Gunnarsson, U. \& Sundberg, S. The role of Sphagnum in peatland development and persistence. Boreal Peatl. Ecosyst. 188, 47-65 (2006).

12. Moore, P. D. The ecology of peat-forming processes: A review. Int. J. Coal Geol. 12, 89-103 (1989).

13. Soudzilovskaia, N. A. et al. Similar cation exchange capacities among bryophyte species refute a presumed mechanism of peatland acidification. Ecology 91, 2716-2726 (2010).

14. Clymo, R. S. Sphagnum-dominated peat bog: a naturally acid ecosystem. Philos. Trans. R. Soc. Lnd. B 499, 487-499 (1984).

15. Gorham, E. \& Janssens, J. A. The paleorecord of geochemistry and hydrology in northern peatlands and its relation to global change. Suo 43, 117-126 (1992).

16. Kuhry, P., Nicholson, B., Gignac, L. D., Vitt, D. H. \& Bayley, S. Development of Sphagnum-dominated peatlands in boreal continental Canada. Can. J. Bot. 71, 10-22 (1993).

17. Vile, M. A. et al. N2-fixation by methanotrophs sustains carbon and nitrogen accumulation in pristine peatlands. Biogeochemistry 121, 317-328 (2014).

18. Tveit, A., Schwacke, R., Svenning, M. M. \& Urich, T. Organic carbon transformations in high-Arctic peat soils: key functions and microorganisms. ISME J. 7, 299-311 (2013).

19. Liebner, S. \& Wagner, D. Abundance, distribution and potential activity of methane oxidizing bacteria in permafrost soils from the Lena Delta Siberia. Environ. Microbiol. 9, 107-117 (2007).

20. Leppänen, S. M., Rissanen, A. J. \& Tiirola, M. Nitrogen fixation in Sphagnum mosses is affected by moss species and water table level. Plant Soil https://doi.org/10.1007/s11104-014-2356-6 (2014).

21. Shcherbakov, A. V. et al. Endophytic bacteria of Sphagnum mosses as promising objects of agricultural microbiology. Microbiology 82, 306-315 (2013).

22. Parmentier, F. J. W. et al. The role of endophytic methane-oxidizing bacteria in submerged Sphagnum in determining methane emissions of Northeastern Siberian tundra. Biogeosciences 8, 1267-1278 (2011).

23. Opelt, K., Berg, C. \& Berg, G. The bryophyte genus Sphagnum is a reservoir for powerful and extraordinary antagonists and potentially facultative human pathogens. FEMS Microbiol. Ecol. 61, 38-53 (2007). 
24. Raghoebarsing, A. A. et al. Methanotrophic symbionts provide carbon for photosynthesis in peat bogs. Nature 436, 1153-1156 (2005).

25. Vicherová, E., Hájek, M., Šmilauer, P. \& Hájek, T. Sphagnum establishment in alkaline fens: Importance of weather and water chemistry. Sci. Total Environ. 580, 1429-1438 (2017).

26. Kumar, M. et al. Plants assemble species specific bacterial communities from common core taxa in three arcto-alpine climate zones. Front. Microbiol. 8, 1-11 (2017).

27. Bragina, A. et al. Similar diversity of Alphaproteobacteria and nitrogenase gene amplicons on two related Sphagnum mosses. Front. Microbiol. 2, 1-10 (2012).

28. Opelt, K., Berg, C., Schönmann, S., Eberl, L. \& Berg, G. High specificity but contrasting biodiversity of Sphagnum-associated bacterial and plant communities in bog ecosystems independent of the geographical region. ISME J. 1, 502-516 (2007).

29. Bragina, A., Berg, C., Müller, H., Moser, D. \& Berg, G. Insights into functional bacterial diversity and its effects on Alpine bog ecosystem functioning. Sci. Rep. 3, 1955 (2013).

30. Bragina, A., Berg, C. \& Berg, G. The core microbiome bonds the Alpine bog vegetation to a transkingdom metacommunity. Mol. Ecol. 24, 4795-4807 (2015).

31. Bragina, A. et al. Sphagnum mosses harbour highly specific bacterial diversity during their whole lifecycle. ISME J. 6, 802-813 (2012).

32. Opelt, K. et al. Investigations of the structure and function of bacterial communities associated with Sphagnum mosses. Environ. Microbiol. 9, 2795-2809 (2007).

33. Sand-Jensen, K., Riis, T., Markager, S. \& Vincent, W. F. Slow growth and decomposition of mosses in Arctic lakes. Can. J. Fish. Aquat. Sci. 56, 388-393 (1999).

34. Gavazov, K. S., Soudzilovskaia, N. A., van Logtestijn, R. S. P., Braster, M. \& Cornelissen, J. H. C. Isotopic analysis of cyanobacterial nitrogen fixation associated with subarctic lichen and bryophyte species. Plant Soil 333, 507-517 (2010).

35. Basilier, K. \& Granhall, U. Nitrogen fixation in wet minerotrophic moss communities of a subarctic mire. Oikos 31, 236-246 (1978).

36. Liebner, S. et al. Methane oxidation associated with submerged brown mosses reduces methane emissions from Siberian polygonal tundra. J. Ecol. 99, 914-922 (2011).

37. Liebner, S. et al. Shifts in methanogenic community composition and methane fluxes along the degradation of discontinuous permafrost. Front. Microbiol. 6, 1-10 (2015).

38. Ikeda, S. et al. Development of a bacterial cell enrichment method and its application to the community analysis in soybean stems. Microb. Ecol. 58, 703-714 (2009).

39. Morris, C. E. et al. A technique to quantify the population size and composition of the biofilm component in communities of bacteria in the phyllosphere. Appl. Environ. Microbiol. 64, 4789-4795 (1998).

40. Bay, G. et al. Boreal feather mosses secrete chemical signals to gain nitrogen. New Phytol. 200, 54-60 (2013).

41. Griffiths, R. I. et al. Rapid method for coextraction of DNA and RNA from natural environments for analysis of ribosomal DNAand rRNA-based microbial community composition. Appl. Environ. Microbiol. 66, 5488-5491 (2000).

42. Herlemann, D. P. et al. Transitions in bacterial communities along the $2000 \mathrm{~km}$ salinity gradient of the Baltic Sea. ISME J. 5, 1571-1579 (2011).

43. Takai, K. \& Horikoshi, K. Rapid detection and quantification of members of the archael community by quantitative PCR using fluorogenic probes. Appl. Environ. Microbiol. 66, 5066-5072 (2000).

44. Martin, M. Cutadapt removes adapter sequences from high-throughput sequencing reads. EMBnet. Journal 10-12 (2011).

45. Zhang, J., Kobert, K., Flouri, T. \& Stamatakis, A. PEAR: A fast and accurate Illumina Paired-End reAd mergeR. Bioinformatics 30, 614-620 (2014).

46. Bolger, A. M., Lohse, M. \& Usadel, B. Trimmomatic: A flexible trimmer for Illumina sequence data. Bioinformatics 30, 2114-2120 (2014).

47. Caporaso, J. G. et al. QIIME allows analysis of high-throughput community sequencing data. Nat. Methods 7, 335-336 (2011).

48. McDonald, D. et al. An improved Greengenes taxonomy with explicit ranks for ecological and evolutionary analyses of bacteria and archaea. ISME J. 6, 610-618 (2012).

49. R Core Team. R: A language and environment for statistical computing. (2015).

50. Greenacre, M. Computation of correspondence analysis. In Correspondance Analysis in Practice (ed. Keiding, N.) 213-259 (Chapman and Hall/CRC, BocaRaton, 2007).

51. Fierer, N. \& Jackson, R. B. The diversity and biogeography of soil bacterial communities. Proc. Natl. Acad. Sci. USA 103, 626-631 (2006).

52. Potter, C. et al. Subtle shifts in microbial communities occur alongside the release of carbon induced by drought and rewetting in contrasting peatland ecosystems. Sci. Rep. 7, 1-14 (2017).

53. Andersen, R., Chapman, S. J. \& Artz, R. R. E. Microbial communities in natural and disturbed peatlands: A review. Soil Biol. Biochem. 57, 979-994 (2013).

54. Jassey, V. E. J. et al. Plant functional diversity drives niche-size-structure of dominant microbial consumers along a poor to extremely rich fen gradient. J. Ecol. 102, 1150-1162 (2014).

55. Zhalnina, K. et al. Soil pH determines microbial diversity and composition in the park grass experiment. Microb. Ecol. 69, 395-406 (2014).

56. Slonczewski, J. L., Fujisawa, M., Dopson, M. \& Krulwich, T. A. Cytoplasmic pH measurement and homeostasis in bacteria and archaea. Adv. Microb. Physiol. 55, 1-79 (2009).

57. Holland-Moritz, H. et al. Novel bacterial lineages associated with boreal moss species. Environ. Microbiol. https://doi.org/10.1093/ annonc/mdy039/4835470 (2018).

58. Xiang, X., Wang, H., Gong, L. \& Liu, Q. Vertical variations and associated ecological function of bacterial communities from Sphagnum to underlying sediments in Dajiuhu Peatland. Sci. China Earth Sci. 57, 1-8 (2013).

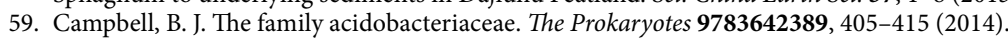

60. Dedysh, S. N., Pankratov, T. A., Belova, S. E., Kulichevskaya, I. S. \& Liesack, W. Phylogenetic analysis and in situ identification of bacteria community composition in an acidic Sphagnum peat bog. Appl. Environ. Microbiol. 72, 2110-2117 (2006).

61. Bulgarelli, D., Schlaeppi, K., Spaepen, S., van Themaat, E. V. L. \& Schulze-Lefert, P. Structure and functions of the bacterial microbiota of plants. Annu. Rev. Plant Biol. 64, 807-838 (2013).

62. Oliverio, A. M. et al. The ecology and diversity of microbial eukaryotes in geothermal springs. ISME J. https://doi.org/10.1038/ s41396-018-0104-2 (2018).

63. Radujkovic, D. Structure of Soil Microbial Communities Along a Geothermal Gradient in Iceland (2016).

64. Rice, S. K. \& Schuepp, P. H. On the ecological and evolutionary significance of branch and leaf morphology in aquatic Sphagnum (Sphagnaceae). Am. J. Bot. 82, 833-846 (1995).

65. Rice, S. K. Patterns of allocation and growth in aquatic Sphagnum species. Can. J. Bot. Can. Bot. 73, 349-359 (1995).

66. Fiala, I. \& Winkler, S. Entwicklungsgeschichtliche Untersuchungen an Sphagnum centrale Jens. Flora oder Allg Bot. Zeitung. Abt. B 158, 390-401 (1969).

67. Mitchell, E. A. D. et al. Structure of microbial communities in Sphagnum peatlands and effect of atmospheric carbon dioxide enrichment. Microb. Ecol. 46, 187-199 (2003). 
68. Liu, X. et al. Insights into the ecology, evolution, and metabolism of the widespread Woesearchaeotal lineages. Microbiome 6, 1-16 (2018).

69. Xiang, X. et al. Distribution of bathyarchaeota communities across different terrestrial settings and their potential ecological functions. Sci. Rep. 7, 1-11 (2017).

70. Wen, X. et al. Global biogeographic analysis of methanogenic archaea identifies community-shaping environmental factors of natural environments. Front. Microbiol. 8, 1-13 (2017).

71. Knief, C. Diversity and habitat preferences of cultivated and uncultivated aerobic methanotrophic bacteria evaluated based on pmoA as molecular marker. Front. Microbiol. 6, 1346 (2015).

72. Osudar, R. et al. Methane turnover and methanotrophic communities in arctic aquatic ecosystems of the Lena Delta Northeast Siberia. FEMS Microbiol. Ecol. 92, 1-13 (2016).

73. Larmola, T. et al. The role of Sphagnum mosses in the methane cycling of a boreal mire. Ecology 91, 2356-2365 (2010).

74. Lüke, C. et al. Macroecology of methane-oxidizing bacteria: The $\beta$-diversity of pmoA genotypes in tropical and subtropical rice paddies. Environ. Microbiol. 16, 72-83 (2014).

75. Lüke, C. Molecular Ecology and Biogeography of Methanotrophic Bacteria in Wetland Rice Fields (Max-Planck-Institut für terrestrische Mikrobiologie, Marburg, 2010).

76. Tveit, A. T., Urich, T. \& Svenning, M. M. Metatranscriptomic analysis of arctic peat soil microbiota. Appl. Environ. Microbiol. 80, 5761-5772 (2014).

77. Vorobev, A. V. et al. Methyloferula stellata gen. nov., sp. nov., an acidophilic, obligately methanotrophic bacterium that possesses only a soluble methane monooxygenase. Int. J. Syst. Evol. Microbiol. 61, 2456-2463 (2011).

78. Dedysh, S. N. et al. Methylocapsa palsarum sp. nov., a methanotroph isolated from a subarctic discontinuous permafrost ecosystem. Int. J. Syst. Evol. Microbiol. 65, 3618-3624 (2015).

79. Dedysh, S. N. et al. Methylocapsa acidiphila gen. nov., sp. nov., a novel methane-oxidizing and dinitrogen-fixing acidophilic bacterium from Sphagnum bog. Int. J. Syst. Evol. Microbiol. 52, 251-261 (2002).

80. Dedysh, S. N. et al. Methylocella tundrae sp. nov., a novel methanotrophic bacterium from acidic tundra peatlands. Int. J. Syst. Evol. Microbiol. 54, 151-156 (2004).

81. Hájek, T., Ballance, S., Limpens, J., Zijlstra, M. \& Verhoeven, J. T. A. Cell-wall polysaccharides play an important role in decay resistance of Sphagnum and actively depressed decomposition in vitro. Biogeochemistry 103, 45-57 (2011).

82. Stalheim, T., Ballance, S., Christensen, B. E. \& Granum, P. E. Sphagnan: A pectin-like polymer isolated from Sphagnum moss can inhibit the growth of some typical food spoilage and food poisoning bacteria by lowering the pH. J. Appl. Microbiol. 106, 967-976 (2009).

83. Basile, A., Giordano, S., Lopez-Saez, J. A. \& Cobianchi, R. C. Antibacterial activity of pure flavonoids isolated from mosses. Phytochemistry 52, 1479-1482 (1999).

84. Rudolph, H. \& Samland, J. Occurrence and metabolism of sphagnum acid in the cell walls of bryophytes. Phytochemistery 24, 745-749 (1985).

85. Berg, G., Grube, M., Schloter, M. \& Smalla, K. Unraveling the plant microbiome: Looking back and future perspectives. Front. Microbiol. 5, 1-7 (2014).

86. Sturz, A. V., Christie, B. R. \& Nowak, J. Bacterial endophytes: potential role in developing sustainable systems of crop production. CRC. Crit. Rev. Plant Sci. 19, 1-30 (2000).

87. Yu, X., Yang, J., Wang, E., Li, B. \& Yuan, H. Effects of growth stage and fulvic acid on the diversity and dynamics of endophytic bacterial community in stevia rebaudiana bertoni leaves. Front. Microbiol. 6, 1-13 (2015).

88. Qin, S. et al. Abundant and diverse endophytic actinobacteria associated with medicinal plant Maytenus austroyunnanensis in Xishuangbanna tropical rainforest revealed by culture-dependent and culture-independent methods. Environ. Microbiol. Rep. 4, 522-531 (2012).

89. Selbmann, L. et al. Culturable bacteria associated with Antarctic lichens: Affiliation and psychrotolerance. Polar Biol. 33, 71-83 (2010).

90. Reiter, B. \& Sessitsch, A. Bacterial endophytes of the wildflower Crocus albiflorus analyzed by characterization of isolates and by a cultivation-independent approach. Can. J. Microbiol. 52, 140-149 (2006).

91. Putkinen, A. et al. Water dispersal of methanotrophic bacteria maintains functional methane oxidation in Sphagnum mosses. Front. Microbiol. 3, 1-10 (2012).

\section{Acknowledgements}

The Arctic University of Norway and the Helmholtz Association of German Research Centres are thanked for funding of an International Research Group (HIRG 0007). Svalbard Science Forum (SSF) is thanked for a field grant to Andrea Kiss. This work was further supported by the Helmholtz Association of German Research Centres through a Helmholtz Young Investigators Group to Susanne Liebner (grant VH-NG-919). Alexander Tøsdal Tveit was supported by the Research council of Norway FRIPRO Mobility grant project Time \& Energy 251027/RU, co-funded by the European Research Council (ERC) under Marie Curie grant agreement no 608695, and Tromsø Research Foundation starting grant project Cells in the Cold 17_SG_ATT. Infrastructure funding through the Terrestrial Environmental Observatories Network (TERENO), specifically through the North-Eastern German Lowland Observatory (TERENO-NE), is also acknowledged. We thank Dyke Scheidemann, Antje Eulenburg, Anke Saborowski and Axel Kitte for laboratory support and Christian Knoblauch, Tiemo Timmermann and Knut Kaiser for field work. We also thank Tiksi Hydrobase staff members, in particular Dmitry Melnichenko, and Waldemar Schneider from the Alfred Wegener Institute for logistics in Siberia. Michael Zauft (Stiftung Naturschutzfonds Brandenburg) is acknowledged for sharing his expertise on brown-moss ecology.

\section{Author contributions}

A.T.T., A.K., T.H. and S.L. conceived the ideas and designed methodology; A.K., M.M.S. and S.L. collected the data; A.T.T., M.W., F.H. and T.H. analysed the data; A.T.T., A.K., M.M.S., D.W. and S.L. led the writing of the manuscript. All authors contributed critically to the drafts and gave final approval for publication.

\section{Funding}

Open Access funding enabled and organized by Projekt DEAL.

\section{Competing interests}

The authors declare no competing interests. 


\section{Additional information}

Supplementary Information The online version contains supplementary material available at https://doi. org/10.1038/s41598-020-79773-2.

Correspondence and requests for materials should be addressed to S.L.

Reprints and permissions information is available at www.nature.com/reprints.

Publisher's note Springer Nature remains neutral with regard to jurisdictional claims in published maps and institutional affiliations.

(c) (1) Open Access This article is licensed under a Creative Commons Attribution 4.0 International cc) License, which permits use, sharing, adaptation, distribution and reproduction in any medium or format, as long as you give appropriate credit to the original author(s) and the source, provide a link to the Creative Commons licence, and indicate if changes were made. The images or other third party material in this article are included in the article's Creative Commons licence, unless indicated otherwise in a credit line to the material. If material is not included in the article's Creative Commons licence and your intended use is not permitted by statutory regulation or exceeds the permitted use, you will need to obtain permission directly from the copyright holder. To view a copy of this licence, visit http://creativecommons.org/licenses/by/4.0/.

(C) The Author(s) 2020 